This is the peer reviewed version of the following article: Abolghasemi, Y, Dimitrov, S. Determining the causality between U.S. presidential prediction markets and global financial markets. Int J Fin Econ. 2020; 1-23., which has been published in final form at https://doi.org/10.1002/ijfe.2029. This article may be used for non-commercial purposes in accordance with Wiley Terms and Conditions for Use of Self-Archived Versions.

\title{
Determining the causality between U.S. presidential prediction markets and global financial markets
}

\author{
Yaser Abolghasemi $^{1^{*}}$ | Stanko Dimitrov ${ }^{1 \dagger}$
}

${ }^{1}$ Department of Management Sciences, University of Waterloo, Waterloo, ON N2L $3 G 1$

\section{Correspondence}

Yaser Abolghasemi, Department of Management Sciences, University of Waterloo, Waterloo, ON, Canada N2L 3G1

Email: abolghasemi@uwaterloo.ca

\section{Funding information}

The Natural Sciences and Engineering Research Council of Canada
Prediction markets trade securities with final prices contingent on the outcome of future events, for example who will win the next political election. We show how the outcome of a United States presidential election, information captured by prediction markets, impacts global financial markets. We investigate the existence of a causal relationship between various prediction markets and global financial markets time series for over 27 different countries and regions using Dow Jones Global Indexes. We construct vector autoregressive models and use the Toda-Yamamoto causality test to deal with non-stationary time series. Preliminary results indicate that prediction markets may be used to predict some global financial markets.

\section{KEYWORDS}

Prediction Market, U.S. Presidential Election, Global Financial Market, Time series Analysis, Toda-Yamamoto Causality Test

\section{1 | INTRODUCTION}

It is always a debate over what forces are shaping the global economy and finance. Recently, World Economic Forum researchers highlighted the following six factors as influences on the global economy in 2016: political populism, refugee crisis, Brexit, Russia's role in the world, weak growth and China's reforms (Borge, 2015). However, it is obvious that most of these factors have a common root which is politics that influence the global economy.

Globalization, as a process of international integration, is widely supported by countries to facilitate global transactions. Despite the growing integration of financial markets, which is a sign of economic globalization, a new gov- 
ernment's policies might contradict with globalization fundamentals. For instance, the ideology of Nationalism, found in various western democracies, affects global financial markets, and may be one cause of the U.S.-China trade war costing global GDP as much as 600 billion dollars Holland and Sam (2019).

The United States (U.S.) has the world's largest economy, forming $24 \%$ of global gross domestic product (GDP), $20 \%$ of global foreign direct investment (FDI), and more $44 \%$ of global stock market capitalization (IMF, 2018). The U.S. stock market value in 2018 was around 30 trillion dollars, which is 5 times bigger than its closest competitor, which is China with 6.3 trillion dollars market capitalization (Hotten, 2019).

Considering the global influence of the U.S. economy, a growth surge in the U.S. economy could lead to a global economic boost. In contrast, uncertainty about the direction of U.S. policies could have the opposite effect. The U.S. presidential election has a significant effect on U.S. financial market performance. In every U.S. presidential election, since 1833, the Dow Jones Industrial Average (DJIA) increased 10.4\% one year before the U.S. presidential elections and $6 \%$ throughout the election year; and the only exception to the found trend is the 2008 U.S. presidential election during which time the DJIA decreased 34\% (Smith, 2016).

The U.S. financial markets' fluctuations caused by presidential elections will affect global financial markets indices. For example, Tokic (2003) investigate the interaction between the U.S. stock market and global financial market, and show a long-run relationship between the U.S. market and Australia, Japan, Hong Kong, New Zealand and Singapore financial markets. In this research we investigate the relationship between the U.S. presidential elections and global financial market indices.

Stock prices correspond to the discounted sum of expected dividends, which is a measure for future economic performance, and any political event (policy or tax) that will benefit the market (its traded firms, stock owners, or market itself) is expected to increase stock prices. Similarly, stock prices are expected to decrease with political events that will harm the market. So, stock price movements are informative as they reflect changes in expectations of future economic performance. By definition, a financial market index change captures changes in the overall market. For a country financial market, as indicated by Aylward and Glen (2000); Harvey (1989); Comincioli (1996) the country financial market index is a leading indicator that helps to measure country's national economic health.

Indeed, U.S. presidential elections impact the U.S. economy, which is an "engine" of the world economy Arora and Vamvakidis (2004). In addition to impacting domestic policies, the party in the oval office determines U.S. policies towards other countries. Considering the fact that a country's well being is measured by its stock market financial index, we determine what is the impact of a U.S. presidential election on other countries' economy, as measured by financial market indices.

Considering the U.S. economic significance, which is the world's largest economy with a gross domestic product (GDP) equal to approximately 24\% of the global GDP in 2018 (IMF, 2018), the U.S. presidential election is always a key recurring political event that has profound consequences for the global economy.

From this perspective, studies that help global economies and financial markets learn existence and direction of relationships between U.S. presidential elections and financial markets can be help to understand future global economic challenges.

To investigate the existence and direction of a causal relationship between the U.S. presidential election outcome and various global financial markets, we use global financial indices, which are among the most important indicators that directly reflect countries or regions' financial health and prospects, and the U.S. presidential election prediction market in our analysis.

Prediction markets are futures markets in which securities are traded with prices contingent on the outcome of future events. The price of prediction market securities at any point in time yields a probabilistic estimate on the likelihood of the contingent event occurring at that point in time (Berg et al., 2003). One of the first electronic prediction 
markets, the lowa Electronic Markets, started in 1988 to predict election outcomes in the United States of America (U.S.). Since their inception, prediction markets have grown in popularity due to their accuracy; prediction markets are shown to be more accurate than survey-based and forecasting approaches and can also address compensation problems in traditional forecasting tools by allowing participants to trade securities (Ho and Chen, 2007). Not only are prediction markets more accurate, they also aggregate information quicker than classical methods (Berg et al., 2008). Therefore, prediction markets are used for constructing robust decision support systems and predictive models (Berg and Rietz, 2003).

This research is motivated by the general quest to determine what and by how much U.S. presidential elections impact world financial and economic systems. Since, prediction market prices provide a point estimate on the probability of an event, U.S. presidential election in our case, occurring at any one point in time, putting the points together generates a time series of probability estimates. Similarly, world economic and financial data are also measured on a second-by-second or minute-by-minute time increment, for example the DOW Jones market indexes.

In particular, we determine the impact US presidential elections have on the global economy as measured by their impact on specific countries and regions financial markets. We use the Toda-Yamamoto (TY) procedure to determine the statistical causal relationship between prediction markets and global financial markets series.

Using the Toda-Yamamoto (TY) procedure, we determine the existence of causal relationships between the predictionmarket and global-financial-markets time series. We additionally derive the direction of causal relationships (lead/lag relationships between variables at different time scales) and the strength of relationships (degrees of correlation). To implement the TY procedure, we have constructed vector autoregressive models (VAR Models) to deal with the integration or cointegration properties of the time series, and we used a modified version of Wald test statistics in the Granger causality test.

To summarize our contribution, we use the TY procedure for causality testing to understand the causal relationships between 27 financial markets, related to various world regions and countries, and the U.S. prediction markets contingent on the outcome of the 2008 U.S. elections. Our research provides insight into how financial markets, under various time granularities, react to the likely outcome of the U.S. presidential election. Finally, with our models we are able to comment on the efficiency of world financial markets, as defined by their ability to incorporate the likely outcome of U.S. presidential elections. Further, we are able to comment on the applicability of the Efficient Market Hypothesis (EMH) when it comes to U.S. presidential elections.

\section{2 | THEORETICAL BACKGROUND}

An efficient financial market is one in which prices fully reflect all available information. Based on Fama's (1991) argument, a financial market is informationally efficient when the probability distribution of future prices, based on investors' relevant information, is equal to the true distribution of prices, considering all existing information in the market. Consequently, the expected returns anticipated by investors are equal to true expected returns. Thus, EMH states that an asset's prices fully reflect all available information, and so it is impossible to beat the market which is not forecastable. In other words, stocks always trade at their fair value, which is based on incorporating all available information, including political information. The next section introduces three different forms of EMH, including the semi-strong form we use in this research.

Based on Jensen's (1978) definition, a market is efficient with respect to a specific information set, $\theta_{t}$, if the investors cannot make more profit by using that information set. That is, as Malkiel (1992) says, the market is efficient with respect to a specific information set, $\theta_{t}$, if revealing that information to all market players does not affect the 
price of shares. In these definitions underscore the importance of information sets, which can be used in financial market trading strategies.

Three forms of the EMH were identified in Fama and Malkiel's (1970) review. The first form, Weak EMH, posits that all price information is fully reflected in the asset prices. In other words, the information set, $\theta_{t}$, contains only past and current asset prices. The second form, Semi-strong $E M H$, requires the inclusion of all available public information, in addition to the asset prices, in the information set. The last form, Strong EMH, asserts that the financial market reflects not only public information, but also private information that a limited number of investors may access.

The Strong EMH has been heavily criticized by a large number of scholars since it is very difficult to verify empirically. Despite the supposedly unbeatable market assumption of the Strong EMH, studies show that stock returns can be predicted by some macroeconomic factors such as interest rate (Balvers et al., 1990; Breen et al., 1989; Ferson and Harvey, 1993). In contrast, Fama and Malkiel (1970) shows that the Weak and Semi-strong forms of EMH are largely supported by empirical studies. Thus, the Semi-strong and Weak forms of EMH are preferred because they mitigate the difficulty of accessing and measuring private information. Additionally, there are two extensions to the EMH that investigates investor reaction when security prices do not adjust instantly: the Overreaction Hypothesis $(\mathrm{OH})$, and the Uncertain Information Hypothesis (UIH) offered by DeBondt and Thaler (1985) and Brown et al. (1988), respectively.

\section{1 | EMH testing}

Despite the full acceptance of the EMH in the finance literature, many studies confirm the weak form of the efficient market hypothesis in different local and regional financial markets, such as Latin America (Urrutia, 1995), Europe (Borges, 2010; Makovskỳ, 2014) and Asia (Kim and Shamsuddin, 2008; Cooray and Wickremasinghe, 2007; Aktas and Oncu, 2006). Furthermore, Gümüş and Zeren (2014) analyze the validity of the EMH in the G-20 countries, and show that the financial markets of the nine countries (the U.S., the U.K., Argentina, Australia, India, Italy, Japan, France and Germany) are efficient in the weak form.

Using the EMH approach, researchers investigate the impact of political event's information on the various financial markets. For instance, Tuck and Hon (2008), using the weak-form of EMH, show that the London Stock Exchange is an efficient market regardless of the political party forming the government. Moreover, Füss and Bechtel (2008) show the effect of 2002 German federal election on its stock returns.

In this research, we use the semi-strong EMH to assess the impact of U.S. presidential elections on global financial markets. The semi-strong form of the EMH may be difficult to test due to interdependence between information source and market (Cooray and Wickremasinghe, 2007); it is hard to determine the information source and if the information is instantaneously incorporated in the market. The volume of evidence supporting the weak form of the EMH suggests that even if markets as slightly inefficiency for a short amount of time, such inefficiencies are quickly corrected, allowing us to leverage the semi-strong version of the EMH in our study. The semi-strong form of EMH allows us to look at the likelihood of the U.S. presidential outcome, as measured by the prediction-market, and see how/if a country's financial market changes with this new information. Similarly, some country's financial markets may capture other information not currently incorporated in U.S. presidential election prediction market (say China purchases trillions of U.S. treasury bonds), and this information may influence the predicted likelihood of the U.S. presidential election outcome. 


\section{I RELATED WORKS AND HYPOTHESES}

In this section we discuss related work to ours and formally state our hypotheses. Generally speaking, the outcome of presidential elections is not known prior to the election. Due to policy differences in the platforms of presidential candidates, the unknown election outcome is equivalent to unknown future policies. Given the connection between presidential election outcome and policy, we first discuss the literature on uncertain economic policy, then we turn our attention to presidential election outcome.

The link between politics and economy is heavily studied in the literature (Foerster and Schmitz, 1997; Alesina and Sachs, 1986; Lamb et al., 1997). Nordhaus (1975) develops the idea of the political business cycles to show the link between the government's policies and economic performance. Moreover, other studies show how macroeconomic outcomes such as unemployment, inflation are affected by a government's policies or political parties' promises (Carlsen, 2000; Hibbs, 1977b). The connection between political events and financial market performance is explored in many studies; in a survey paper Wisniewski (2016) introduces multiple studies that explore the links between politics and stock returns.

Among different political events, elections are potentially most important since economic policies are contingent on the outcome, leading to economic uncertainty prior to the election. Pantzalis et al. (2000) discuss the importance of the presidential election by arguing that elections empower voters to affect the course of economic policies and attract media attention that facilitates information dissemination into financial markets. Foerster and Schmitz (1997) and Foerster (1993) discuss the idea of the presidential election cycle, and they show that the U.S. stock market outperforms in the last two years of a presidential term. Moreover, the relationship of stock market movements and presidential elections outcome is studied by others (Chiu et al., 2005; Gemmill, 1992; Steeley, 2003; Brüggelambert, 2004). Additionally, there are several other studies which investigate the impact of other political uncertainties, such as strike, sanctions, terrorist attack, and legislation changes on financial markets (Bittlingmayer, 1998; Kim and Mei, 2001; Lin and Wang, 2004). A large and growing body of literature investigates the impact of the political environment on macroeconomic outcomes. For example, Hibbs (1977b) describes the role of partisanship policies on economic outputs, such as unemployment and inflation rates. Roubini and Sachs (1989) and De Haan and Sturm (1994) argue that a left-wing government has higher government spending. Similarly, Volkerink and De Haan (2001) show that right-wing administrations are more financially responsible. Our work fits in within the literature on the link between politics and the economy, and spans three streams of literature: 1) the impact of political elections on financial markets 2) political uncertainty and economic activity and 3) ex-post and ex-ante analysis of political events. We will discuss each of these three streams of literature in turn in our paper.

We start by discussing the first stream of literature. Economic researchers attempted to evaluate the impact of a coalition government on economic outputs. They show that as coalition size grows (as measured by the number of political parties in the coalition), then so does public debt (Bawn and Rosenbluth, 2006; Persson et al., 2003; Alesina and Perotti, 1996).

Many financial market experts affirm that the U.S. stock market achieves better financial returns under Republicans than Democrats. For example, Niederhoffer et al. (1970) uses presidential election data from 1900 to 1968 and shows whenever the Republican won the elections, then the stock market performed better the day after the election. This finding, regarding the day-after market performance, is challenged in the literature by studies that investigate the relationship between political partisanship and financial markets in the short and long term.

The literature on short-term election impact considers the movement of market returns for a given investor's expectation of future government, which might be a right-wing or left-wing administration (Oehler et al., 2013; Roberts, 1990a; Białkowski et al., 2008; Sturm, 2009; Homaifar et al., 1988). Additionally, Homaifar et al.'s (1988) investi- 
gates the defense-related industries' stock price movement in the period surrounding an election. The literature on long-term election impact mainly focuses on the relationship between political partisanship and stock markets in the long-term (Allvine and O'Neill, 1980; Huang, 1985; Foerster and Schmitz, 1997). These studies reinforce the idea of the political business cycle offered by Nordhaus (1975). Additionally, Stovall (1992) shows that the U.S. stock market returns are higher, specifically in the second half of the presidential terms, when the Republican party is in power. In contrast, Santa-Clara and Valkanov (2003) show that the Democrat's administration is better for the U.S. stock market returns, in which the average excess return from 1927 to 1998 under the Democrats and the Republicans are 2 and 11 percent, respectively.

Much of the previous research focused on the impact of political events on the U.S. stock market. However, there is a relatively large body of literature that investigates the other country's stock market. For example, Hudson et al. (1998) show that the U.K. stock market performs better under a right-wing government than a left-wing government; however, Döpke and Pierdzioch (2006) show that the German stock market is not sensitive to the political party in power; Cahan et al.'s (2005) argue that the New Zealand stock market's return was higher during right-wing administrations from 1931 to 2003 than left-wing administrations during the same period; and Wang and Lin (2008); Hung et al. (2007) empirically analyze that the congressional election has a negative effect on Taiwan stock returns. Further, Furió and Pardo (2012) support partisan politics theory since Spain's stock returns movement depends on the government's political orientation. Subsequently, Chiu et al. (2005) investigates the impact of political elections on foreign investor's trading behavior on the South Korea stock market.

Of the fist stream of literature that considers the impact of a domestic election on domestic financial market, none of them consider a prediction market as the estimate of the election. We revisit this idea when we discuss different lenses one may use when investigating political events (ex-ante vs. ex-post, see the end of this section). Moreover, as previously stated we consider the impact of U.S. elections on non-U.S. financial markets, i.e., domestic elections on non-domestic markets, something that to our knowledge is not explored previously.

We now move to the second stream of literature on political uncertainty and economic activity. Numerous studies find a negative effects of policy uncertainty on economic activity. For instance, Liu and Zhang (2015); Wang et al. (2014); Karnizova and Li (2014); Colombo (2013) discuss the financial aspects of economic policy uncertainty. Davis (2016) considers global economic policy uncertainty, a specific type of economic policy uncertainty, and develops the economic policy uncertainty (EPU) index based on newspaper coverage frequency. Furthermore, Baker et al. (2016) expands the EPU index to create a monthly index of Global Economic Policy Uncertainty (GEPU). Unlike our work, Davis (2016); Baker et al. (2016) use newspaper coverage to measure uncertainty, instead we use prediction market data.

Another manifestation of policy uncertainty is government policy uncertainty, for example associated with different presidential candidates. Pástor and Veronesi (2013) investigate the relationship between government policy, as written in news outlets, and stock prices. The authors conclude that increased government policy uncertainty leads to increased stock-market volatility.

As previously mentioned, presidential elections are a source of uncertainty. This suggests, that not only does uncertainty need to be quantified, in the form of risk, but also its impact on metrics of interest, for example financial markets, must be captured. Kelly et al. (2016) consider the impact of major political events on financial markets. The authors develop a model to isolate political uncertainty by exploiting its variation around major political events such as presidential elections. Kelly et al. conclude that major political events impact the equity options markets, and the effect spills over across countries, not just the country with the major political event. Our work differs from Kelly et al.'s (2016) study as the authors do not quantify the risk associated with the major political event, which we do using prediction market data. In addition, the authors use correlation analysis between political events and market 
data, instead we use time-series causality in our analysis. Considering the effect of a presidential election, the US election in our case, as a source of economic policy uncertainty, the remainder of this section discusses the economic analysis of elections and presents our hypotheses.

Our study relates to the stream of literature on political uncertainty and economic activity because presidential elections are a type of political uncertainty (which party will be in power). The literature in this stream proposes multiple measures for political uncertainty, but we are unable to find a single measure for presidential elections. In our study we use the instantaneous probabilities, as measured by prediction markets, as the measure for the political uncertainty associated with U.S. presidential elections.

We now turn our attention to the third stream of literature on ex-post and ex-ante analysis of political events. The relationship between economic variables and presidential election politics has been investigated in a significant number of studies. As a general overview, the literature divides into two main approaches, ex-post and ex-ante analysis of elections. The first group of studies, ex-post analysis, tries to find a connection between the election outcomes, the winner's political partisanship, and different macroeconomic variables (Fair, 1978; Fiorina, 1991; Bartels, 1988; Hibbs, 1987, 1977a; Erikson, 1989; Jacobson, 1990; Alesina and Roubini, 1992). In addition, Rogoff (1990); Alesina and Roubini (1992) studied political-business-cycle theories to understand how incumbent politicians try to manipulate the economy to increase their chance of re-election. Furthermore, Jacobson (1990); Alesina and Roubini (1992); Alesina and Rosenthal (1995); Hibbs et al. (1996) have shown the impact of partisan control of government on economic outcomes. Other studies are made more accurate through using econometric models and time series analysis to highlight the relationship between election and particular economic sectors over a period. Unlike our work, in which we consider election predictions and not the realized outcome, all ex-post studies only consider the realized election outcome in their studies.

In addition to ex-post analysis, which is based on actual election results rather than forecasts, there are a few studies that take the ex-ante approach by using prediction-market data. Since the emergence of prediction markets, researchers have tried to use information aggregated by the prediction market in their economic analysis. Prediction markets are useful in drawing inferences about future events directly. However, many researchers have studied the relationships of prediction market data to other economic variables. In most cases, a time series of a particular contract in a prediction market is created and tested in an econometric model that has other economic variables. For instance, Roberts (1990b) studied the relationship between the daily rate of return for 58 defense industry securities and the probability that Ronald Reagan would win the 1980 presidential election. Prediction market data was obtained from an odds market managed by a famous odds maker, Ladbrokes, of that time. The author shows a significant relationship between returns for those defense firms and the probability of Ronald Reagan winning the election.

Herron et al. (1999) analyzed the link between the United States presidential election outcome, based on the 1992 lowa Political Stock Market, and 15 different economic sectors, by selecting related Dow Jones Industry Group Indices to pinpoint those economic sectors that significantly correlated with the election outcome. Similarly, Knight (2004) used lowa Political Stock Market prices to demonstrate how policy platforms capitalize on companies' stock prices by analyzing daily data of 70 firms during the six months prior to the 2000 U.S. election. Moreover, Snowberg et al. (2007) precisely estimate the response of equity, currency, and bond prices to changes in the majority party in the 2006 midterm U.S. Congress elections.

Our research, an ex-ante study, is not based on the actual election results, but uses prediction market data as an accurate forecaster of election outcomes in its analysis. To our knowledge, this is the first study to investigate the causal relationships between U.S. presidential elections and global financial markets. Moreover, it is the first to use intra-day time series in its analysis. This research differs from other ex-ante studies in that it uses prediction market data, as a time series in its causality analysis, instead of surveys and polls. The prediction markets are known 
to have more accurate forecasts than polls and surveys (Berg et al., 2008; Rothschild, 2009). In addition, prediction markets provide real-time continuous information about the election outcome, whereas polls and surveys provide only a snapshot fixed in time of an election's likely outcome.

\section{1 | Research hypotheses}

Roberts (1990b) articulates his research hypothesis about the expectation that future defense spending of 58 defense firms was contingent on the election of Jimmy Carter or Ronald Reagan in 1980. The results of the hypothesis tests show a direct relationship between the probability that Reagan wins the election and the expected increase in the returns of 58 defense firms.

Herron et al. (1999) hypothesized that, among 74 economic sector portfolios, no sector would be politically sensitive to the 1992 US presidential election outcome. However, when the authors tested the sensitivity of sectors thought to be politically sensitive, they found that there was, indeed, a correlation between the outcome of the election and some politically sensitive sectors.

Knight (2004) determined the causal relationship between the outcome of the 2000 US elections, and the price of 70 securities that the author identifies as either Bush-favoring or Gore-favoring. Also, Snowberg et al. (2007) explored financial market responses to the outcome of the 2006 midterm election by investigating the extent to which partisan majorities in Congress influenced economic policy.

Most of the literature looks at the relationship between U.S. election outcomes and domestic financial markets. In our work, however, we will present both the existence and direction of relations between the outcome of U.S. elections on global financial markets. We use prediction market data to identify the real-time probability estimate on the outcome of the elections. Similarly, we use a market index to determine the real-time value of an entire regional or country specific financial market.

In this research, each hypothesis had been constructed for the different set variables related to a particular prediction market and global financial market time series. For example, if we choose "Democratic Party Candidate to Win 2008 Presidential Election" (DEM2008) as a prediction market variable and choose "Dow Jones Canada Index" (CADAWD) as a financial market variable, then the general form of the null and alternative hypothesis of the Granger causality test are as follows:

$$
\begin{gathered}
\text { Lead Hypotheses }= \begin{cases}H_{0}: & \text { DEM2008 does not Granger cause CADOWD } \\
H_{1}: & \text { DEM2008 does Granger cause CADOWD }\end{cases} \\
\text { Follow Hypotheses }= \begin{cases}H_{0}: & \text { CADOWD does not Granger cause DEM2008 } \\
H_{1}: & \text { CADOWD does Granger cause DEM2008 }\end{cases}
\end{gathered}
$$

The Lead hypothesis investigates the existence of relationships between the prediction market and financial market, in which a prediction market leads a financial market. In contrast, the Follow hypothesis investigates those situations in which a prediction market follows a financial market.

Lead and Follow hypotheses have been tested for 594 pairs, generated by the combination of two prediction markets, 27 financial markets in 11 different time series granularities. Two iterative testing strategies, Rolling Day and Moving Window (see section 5.2), were used to test the hypotheses over 790,000 times. The Rolling Day strategy tested over 430 iterations per pair; and the Moving Window strategy tested 1030 times per pair. 
Finally, we aggregated the results of the 790, 000 tests in the following mutually exclusive causal relationships (in which PM stands for Prediction Market and SM stands for Stock Market/Financial Market):

- Lead Effect (PM $\rightarrow \mathrm{SM}$ ): a unilateral causal relationship exists by which changes in prediction markets lead to changes in financial markets; consequently, prices in prediction markets affect prices in financial markets.

- Follow Effect (SM $\rightarrow$ PM): a unilateral causal relationship exists by which changes in financial markets lead to changes in prediction markets; consequently, prices in prediction markets follow prices in financial markets.

- Feedback Effect (PM $\leftrightarrow$ SM): a bilateral causal relationship exists between financial markets and prediction markets, so both markets affect each other at the same time.

- Neutral Effect $(P M \otimes S M):$ a neutral causal relationship exists between financial markets and prediction markets, which means that the two types of markets are independent of each other and there is no causal relationship.

\section{4 | DATA DESCRIPTION}

We use different data sets relevant to this research: prediction market data and global financial data. Prediction market data show electoral probabilities from the United States 2008 presidential election campaign, for both the Democratic and Republican parties led by Barack Obama and John McCain, respectively. Global financial market data were selected from 27 different countries or regions' Dow Jones Global Indices during the same election campaign period (the list of all 27 indices is presented at the end of section 4.2 ).

\section{1 | Prediction Market Data}

The first set of data was acquired from the intrade.com website. Intrade, founded in 1993, was later acquired by Tradesports in 2003. The Intrade website was eventually shut down in March 2013. Intrade was a prediction-market trading exchange that had different contracts for many political events. Among the Intrade electoral contracts, we choose DEM2008 and REP2008, which are interpreted as the probabilities assessed by all market participants of a Democratic party victory and a Republican party victory in the 2008 US presidential elections, respectively.

Each prediction market time series starts at the beginning of 2006 and ends on November 4, 2008, which was the United States presidential election date. Figure 1 shows the movement of the two parties' winning probabilities.

Intrade contracts represent a "winner-takes-all" type (a winner is paid 100 cents for each winning contract held), in which a contract's price represents the expected probability of an event outcome. As Figure 1 shows, both parties started with a winning probability of $50 \%$, and traders aggregated all information into the share's prices during the campaigning. By Intrade prediction market's design, players were free to trade contract shares any time to make sure that the trader's information was aggregated as soon as possible, and the winner took all the value of its contracts. Eventually, the price of the Democratic party approached 100, and the price of the Republican party approached 0 on election day.

\section{2 | Global Financial Market data}

The second category of data in this research consists of the minute-by-minute indices for 27 countries, available in the Dow Jones Global Indices (DJGls) family. One important feature of DJGls is the comprehensive coverage of each country across different economic sectors. Therefore, we assume that DJGls are the proxy of the overall financial 
FIG URE 1 Intrade Prediction Market Data - 2008 U.S. election

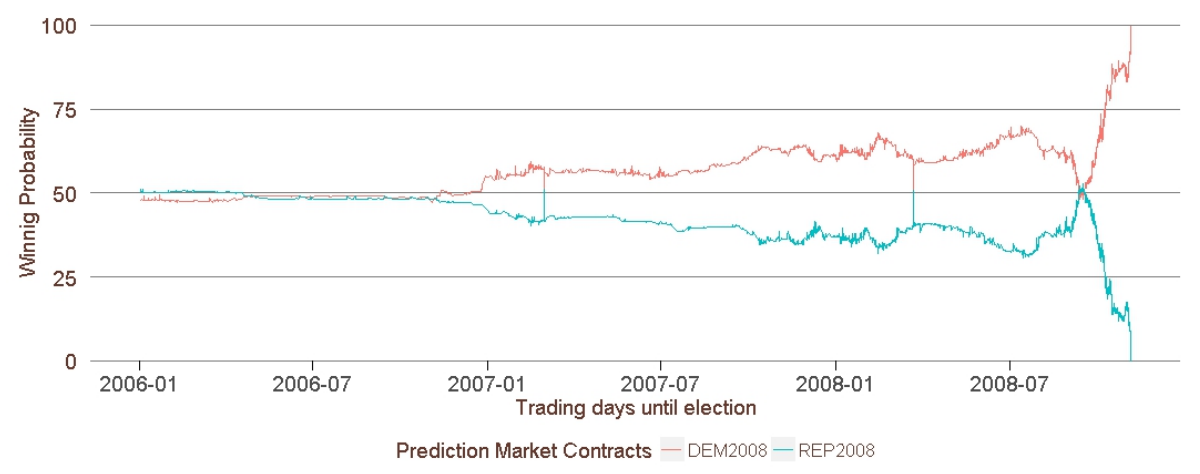

market's situation.

DJGIs indices are weighted by float-adjusted market capitalization, in which the indices calculation utilize the divisor methodology used in all S\&P Dow Jones Indices' equity indices (Jones, 2019). The formula to calculate capitalization-weighted indices, such as all DJGIs indecies, is as follows:

$$
\text { Index Level }=I=\frac{\sum_{i} P_{i} * Q_{i}}{\text { Divisor }}
$$

where $P_{i}$ is price of each stock and $Q_{i}$ is the number of shares used in the index calculation. The denominator is the divisor, for example when the sum of the numerator is US $\$ 25$ trillion and the divisor is US \$10 billion, the index level will be 2500 . Moreover, In the float-adjusted weighted methodology, a change in the index level is defined by a LasPeyres index as follows:

$$
\text { Index Level Change }=\frac{I+\Delta I}{I}=\frac{\sum_{i} P_{i, 1} * Q_{i, 0}}{\sum_{i} P_{i, 0} * Q_{i, 0}}
$$

where I is the index level; $P_{i}$ and $Q_{i}$ are price and the float adjusted share count of asset $i$. Based on equations (4) and (3), total returns indices are defined as follows:

$$
\frac{I_{T R, t}}{I_{T R, t-1}}=\frac{I_{t-1}+\Delta I_{t}+\sum_{i, t}\left(D_{i, t} * Q_{i, t}\right)}{I_{T R, t-1}}
$$

where $I_{T R}$ is the total return index level and $D_{i, t}$ is the dividend for asset $i$ on dividend ex-date (reinvestment date) $t$. In particular, to figure the rate of return, we need to know the starting price and ending price for the index for a specific period of time.

In this research, we use DJGls level data in our time-series analysis as descried above. However, we take first difference of all index time series to correct the non-stationary issues discussed on the Section 5 . As such we are looking at price changes in each index and comparing these to changes in the probability of the presidential election outcome.

All selected DJGls indices are calculated in U.S. dollar currency and contain trading days from January 1, 2006, to November 4, 2008. We have kept non-trading days as we have them in the prediction market time series as well. 
The original intraday historical data, acquired from www . kibot. com, is in five-minute granularity, and we created other time series with different time granularities based on the original time series.

The selected Dow Jones indices time series are as follows: Americas (A1DOW), Latin America (A3DOW), Latin America ex-Mexico (A3DOW), Austria (ATDOWD), Australia (AUDOWD), Belgium (BEDOWD), Brazil (BRDOWD), Canada (CADOWD), Germany (DEDOWD), Denmark (DKDOWD), Europe (E1DOW), Europe ex-U.K. (E2DOW), Europe - Nordic (E3DOW), Finland (FIDOWD), France (FRDOWD), Greece (GRDOWD), Hong Kong (HKDOWD), Indonesia (IDDOWD), Ireland (IEDOWD), Italy (ITDOWD), Japan (JPDOWD), Mexico (MXDOWD), Malaysia (MYDOWD), Netherlands (NLDOWD), Norway (NODOWD), New Zealand (NZDOWD), China (DJCHINA). ${ }^{1}$

\subsection{Time series pairs, granularity and transformation}

To investigate the relationship of the global financial markets and the U.S. presidential prediction markets, we matched the prediction market time series (DEM2008 and REP2008) with the closing price, the end of the time granularity considered, of the selected DJGI indices. The process of creating time series is as follows:

1. Pairs: considering two prediction markets series and 27 financial indices, we created 54 pairs of time series. For example, the CADOWD-DEM2008 series is the combination of the Dow Jones Canada Index stock market time series and the prediction market time series for the Democratic Party Candidate to Win 2008 Presidential Election. The new time series has a time stamp, corresponding to the selected time granularity, and the closing prices for both the stock market and prediction market time series.

2. Granularity: we aggregated pairs of time series to 11 different frequencies in the standard open-high-low-close $(\mathrm{OHLC})$ format. We generated time series of 5, 10, 15 and 30-minute intervals, and time series of 1, 2, 4, 8, 12 and 16-hour intervals. Finally, we created a daily time series for each pair. In total we used 594 pairs of time series in our empirical analysis based on closing prices for each time interval considered.

3. Filling gaps: pairing prediction-market and financial-market time series of various granularity may generate some gaps in both time series. For example, in a weekday, we have financial market price data for every 5 minutes, but we might have no data for the same times in the prediction market. In such a case, we fill the time series gaps with the closest previous price.

4. Transformation: we use the natural logarithmic transformation of all time series to make elasticity calculation easier, by allowing us to interpret small changes in the transformed variables as percentage changes. In addition, such logarithmic transformation can help to stabilize the variance of the time series as shown by Lütkepohl (2005).

\section{5 | STATISTICAL METHODS}

This section highlights the statistical methods used to investigate the relationship between the U.S. election prediction markets and the selected global financial markets.

Generally, the basic approach currently used in research on causality between variables is the Granger causality test, which is based on Granger's (1969) original work.

Granger causality testing is heavily used in the literature to understand the existence of causal relationships, to infer causality directions, and to identify lead and lag variables. Many other researchers have expanded Granger's idea

\footnotetext{
${ }^{1}$ For more information on Dow Jones Global Indices ${ }^{\circledR}$ and download a comprehensive list of all DJGI indices, visit the following website: https://ca . spindices.com/documents/index-policies/dj_vendor_codes.xls?force_download=true
} 
and offered some improvements, including Sims (1972), Toda and Yamamoto (1995), Dufour and Renault (1998), Lütkepohl (2005). But, conventional Granger causality test has some limitations as follows:

- Granger causality requires time-series to be stationary. However, it is well known financial time series are not stationary (Maddala and Lahiri, 2001) and as such conventional Granger causality testing suffers from problems such as spurious regression results (Gujarati and Porter, 2009). Also, Gujarati and Porter argue that the F-test is not valid when the variables are cointegrated.

- Granger causality test is sensitive to model specification and the number of lags. Granger testing would reveal different results if a causal factor was relevant and was not included in the model (Seth, 2007; Gujarati and Porter, 2003).

- Hu et al. (2012) discuss the Granger causality's shortcomings in time domain (i.e., Auto-regressive models) and show how Granger causality testing fails to determine the strength of causality when there is bi-directional causality between two time series.

To remedy the non-stationary problem, the Error-Correction Model (ECM) and the Vector Autoregression ErrorCorrection Model (VECM) are respectively offered by Engle and Granger (1987) and Johansen and Juselius (1990) as alternatives to conventional Granger causality testing. However, these alternative tests are highly sensitive to the value of parameters in finite samples and also to the results of some pretests, such as the unit roots and cointagrating ranking necessary in these tests. Distortions may, therefore, occur associated with non-stationary and cointegration pretests. Due to these distortions, we avoid using ECM and VECM tests as results from these tests may not be reliable due to the lack of usual asymptotic distribution in integrated or cointegrated series (Toda and Yamamoto, 1995; Zapata and Rambaldi, 1997; Rambaldi and Doran, 1996).

All things considered in this study, we use the Toda-Yamamoto causality test, which is an adjusted Granger noncausality test, proposed by Toda and Yamamoto (1995) to address non-stationary and co-integration problems of financial time series. Also, we consider a Zivot-Andrew test to detect any structural break. In the next section, we briefly discuss TY procedure.

\section{1 | Toda-Yammamoto causality test procedure}

The limitations of the the Granger causality test due to non-stationary time series could lead to spurious regression problems. Furthermore, when the variables are integrated or cointegrated, the common F-test process is not valid since the test statistics do not have a standard distribution.

The Toda-Yamamoto test came about in order to fix the problems of invalid asymptotic critical values when we use causality tests with non-stationary or cointegrated time series.

Toda and Yamamoto (1995) proposed a simple procedure requiring the estimation of a VAR model, which guarantees the asymptotic distribution of the Wald statistic that has asymptotic $\chi^{2}$ distribution. The TY testing procedure can deal with the integration or cointegration properties of the process. The Toda-Yamomato Granger causality test is an augmented VAR model for two time series, $x$ and $y$, as follows:

$$
x_{t}=a+\sum_{i=1}^{k} \alpha_{1 i} x_{t-i}+\sum_{i=k+1}^{k+d_{\max }} \alpha_{2 i} x_{t-i}+\sum_{i=1}^{k} \beta_{1 i} y_{t-i}+\sum_{i=k+1}^{k+d_{\max }} \beta_{2 i} y_{t-i}+u
$$




$$
y_{t}=a+\sum_{i=1}^{k} \gamma_{1 i} y_{t-i}+\sum_{i=k+1}^{k+d_{\max }} \gamma_{2 i} y_{t-i}+\sum_{i=1}^{k} \delta_{1 i} x_{t-i}+\sum_{i=k+1}^{k+d_{\max }} \delta_{2 i} x_{t-i}+u
$$

The TY procedure suggests creating a lag augmented $\operatorname{VAR}\left(k+d_{\max }\right)$ by using a modified version of Wald test statistics (MWald) that has an asymptotic $\chi^{2}$ distribution. In this case, $d_{\max }$ is the maximal order of integration and $k$ is the optimal lag length of the system. In this approach, the VAR model with the correct order of $k$ is augmented by the maximum order of integration, $d_{\max }$, and we ignore the coefficients of last $d_{\max }$ lags. So, " $y$ does not Granger cause $x$ " implies that in equation (6) $\beta_{11}=\beta_{12}=\ldots=\beta_{1 k}=0$; similarly, in equation (7), " $x$ does not Granger cause $y$ " if $\delta_{11}=\delta_{12}=\ldots=\delta_{1 k}=0$.

As Figure 2 shows, to implement the TY procedure, we follow three main steps:

1. Identifying the maximum order of integration, $d_{\max }$;

2. Determining the optimal lag length, $k$;

3. Testing for Granger causality, using modified Wald test for $\operatorname{VAR}\left(k+d_{\max }\right)$.

\subsection{1 | Step 1- Identifying the maximum order of integration}

Order of integration, $I(d)$, is the minimum number of differences required to obtain a stationary time series. To determine whether a time series is stationary or not, we use a unit root test. If the unit root test result shows a degree of integration in the selected time series, then we difference the time series, meaning that we compute the differences between consecutive observations and retry the unit root test. We continue differencing until we produce a non-stationary time series. Finally, the number of times we must make a difference is the order of integration.

Finding the order of integration must be done for series available in the VAR model, and we select the maximum order as the VAR's maximum order of integration. For example, if we have $I$ (1) for a prediction market series and $I$ (2) for a financial market series, then the VAR's maximum order of integration will be $I(2)$.

To investigate unit root in our time series we use three different tests: The augmented Dickey-Fuller (ADF) test offered by Dickey and Fuller (1979), the Phillips-Perron (PP) test offered by Phillips and Perron (1988), and the Kwiatkowski-Phillips-Schmidt-Shin (KPSS) test offered by Kwiatkowski et al. (1992).

Selecting the true lag length, $p$, in an ADF test is important. Too small a lag length will cause serial correlation in the error terms and thereby bias the test results. On the other hand, choosing a large lag length will reduce the power of the test (Zivot and Wang, 2006). Moreover, according to Gujarati and Porter's (2003) argument, selecting too many lags in the model will decrease the degrees of freedom and cause over-fitting and multicollinearity (correlation of the independent variables) problems, whereas choosing too few lags will lead to specification errors (correlation of the independent variables with the error term). The common strategy for handling this issue is using the information criteria offered by many scholars, such as AIC (Akaike, 1973), BIC (Schwarz, 1978), and HQ (Hannan and Quinn, 1979).

Based on Gonzalo and Pitarakis (2002), penalty term in the AIC leads to a non-zero limiting probability of over fitting when $T \rightarrow \infty$, where $T$ represents the total number of observations. Furthermore, Davidson and MacKinnon (2004) found that the AIC criterion may fail to choose the most parsimonious model (i.e., the model with the fewest parameters to estimate). BIC, however, might lead to an overly parsimonious situation by under fitting the model. Additionally, Gonzalo and Pitarakis (2002) show that BIC and HQ lead to consistent estimates and are better than AIC in models with a large number of observations.

Considering the controversial problems of over fitting and under fitting a model by using the traditional IC, $\mathrm{Ng}$ 
FIG URE 2 Toda-Yamamoto Causality Test Procedure

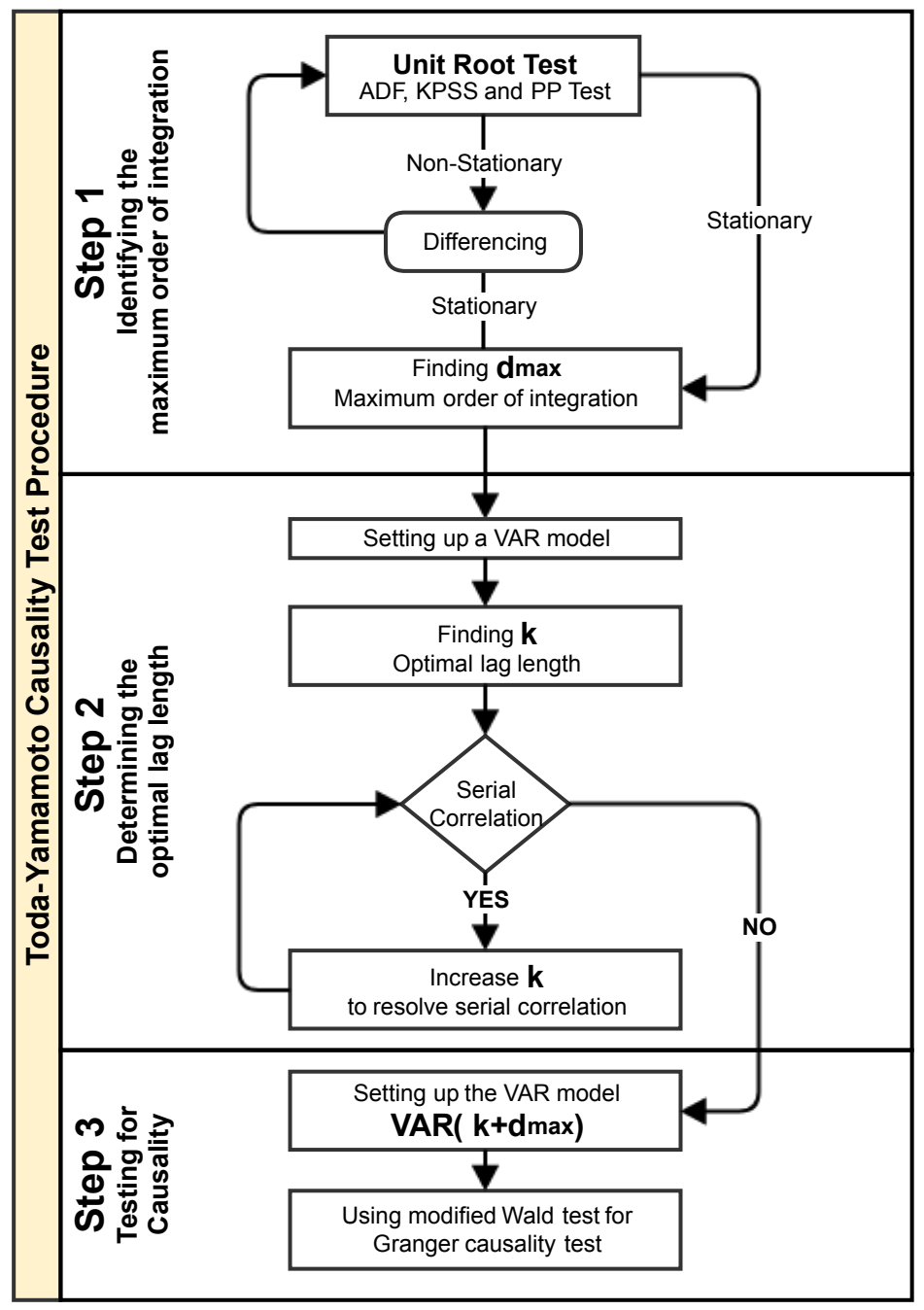

and Perron (2001) proposed a modified information criterion ( $\mathrm{mIC}$ ) to consider a good size and power of unit root test in selecting true lag length. Therefore, in this research, we use mAIC information criterion to choose an appropriate lag length in the ADF unit root test as follows:

$$
\operatorname{mAIC}(p)=\ln \left(\hat{\sigma}_{p}^{2}\right)+\frac{2\left(\tau_{T}(p)+p\right)}{T-p_{\max }}
$$


Where:

$$
\tau_{T}(p)=\frac{\hat{\pi}^{2} \sum_{t=p_{\max }+1}^{T} y_{t-1}}{\hat{\sigma}_{p}^{2}} \quad \text { and } \quad \hat{\sigma}_{p}^{2}=\frac{1}{T-p_{\max }} \sum_{t=p_{\max }+1}^{T} \hat{\varepsilon}_{t}^{2}
$$

To calculate mAIC in equation (8), we need to determine $p_{\max }$, which is the maximum lag length needed to calculate ICs for finding the appropriate lag length. Schwert (2002) suggests a rule of thumb, which is investigated with a Monte Carlo study, to determine $p_{\max }$ as follows:

$$
p_{\max }=12 \times\left(\frac{T}{100}\right)^{\frac{1}{4}}
$$

There is a three-step process for finding $p: 1$ ) calculate $p_{\max }, 2$ ) calculate mAICs for lag length from 1 to $p_{\max }$, and 3) select the best $p$ where mAIC is the minimum number.

The other two unit root tests, Philips-Peron (PP) and Kwiatkowski-Phillips-Schmidt-Shin (KPSS), are used to cross check the result of ADF testing. Hobijn et al. (2004) argue that ADF unit root testing has low power against stationary and highly auto-regressive series. In other words, we may not find the stationarity of a series with ADF testing. To deal with highly auto-regressive models, Hobijn et al. argued the good performance of the KPSS test based on a Monte Carlo investigation. Moreover, ADF testing assumes that $u_{t}$ is a stationary white noise process and addresses the serial correlation of error terms by adding some lagged variables into the model. Whereas we have some challenges to determine true lag length, Mahadeva and Robinson (2004) argue some advantages of PP testing over ADF testing because the former's non-parametric approach does not need to select any lag length to address serial correlation problems in the error term.

Therefore, in this research, we conclude the non-stationary property of our time series when the results of all three tests (ADF, PP and KPSS) unanimously confirm the non-stationarity of the selected time series. If they do not agree, then we flag that test and do not continue the TY process.

\subsection{2 | Step 2- Determining the optimal lag length}

After determining $d_{\max }$ in the first step of the TY process, we need to find the optimal lag length of the VAR model, which includes the following tasks:

1. Selecting the lag length, $p$, based on the information criterion.

2. Checking for the possible serial correlation of the $\operatorname{VAR}(p)$ model.

\section{First task: VAR lag order selection}

In the first task for VAR model lag-order selection, we use the BIC and HQ information criteria based on Scott Hacker and Hatemi-J's (2008) simulation study that finds BIC and HQ have the best performance in many cases. First, we determine the maximum lag length, $p_{\max }$, by the rule of thumb presented in equation (10). Second, we calculate HQs and BICs for VAR( 1$)$ to VAR $\left(p_{\text {max }}\right)$. The minimum number of calculated BICs and HQs will help us to understand the offered lag orders, $p_{B I C}$ and $p_{H Q}$, based on both information criteria. If $p_{B I C}=p_{H Q}$, then we can determine the VAR model lag length, $p$, as $p=p_{B I C}=p_{H Q}$. Otherwise, if $p_{B I C} \neq p_{H Q}$ we use a Likelihood Ratio (LR) test to choose the VAR model lag length, $p$, from $p_{B I C}$ or $p_{H Q}$. This LR test is recommended by Hatemi-J and S. Hacker (2009) when ICs suggest different lag orders for a VAR model. 


\section{Second task: Serial correlation}

In the second task, we have to make sure that the residual of the $\operatorname{VAR}(p)$ is not correlated with independent variables. If we find serial correlation in our $\operatorname{VAR}(p)$ model, we need to increase the order of the VAR model to $p+1$ and test it for serial correlation. This process must repeated until the serial correlation problem is resolved in the VAR model.

This research uses the Bruech-Godfrey (BG) test, which is offered by Breusch (1978); Godfrey (1978), to test serial correlation of the VAR models. We use Breusch-Godfrey test to check the possible serial correlation of VAR models for up to 10 lags. The choice of 10 lags for an autocorrelation test is based on Hyndman and Athanasopoulos's (2014) suggestion when dealing with non-seasonal data.

\subsection{3 | Step 3- Testing for Granger causality}

In conventional Granger causality tests, zero restrictions on the coefficients can be checked by the Wald test, which has asymptotic $\chi^{2}$ distribution, a standard tool for VAR models, when we have stationary data. However, according to Toda and Yamamoto (1995), if the time series are integrated or cointegrated, then the standard asymptotic theory is not applicable and the standard Wald test-statistic does not have asymptotic $\chi^{2}$ distribution in the level VAR (the original VAR model with no differencing). We thus create $\operatorname{VAR}\left(p+d_{\max }\right)$ and use Wald test for the first $p$ variables without considering $d_{\max }$ lags. This method guarantees the asymptotic distribution of the Wald statistic, which is asymptotically $\chi^{2}$ distributed with $p$ degrees of freedom under the null hypothesis.

\section{2 | TY testing strategies}

We implemented the TY procedure with two different iterative strategies, Rolling Day and Moving Window as follows:

\subsection{1 | Rolling Day Strategy}

With the first strategy, Rolling Day, in each iteration we exclude observations related to the first day of the original time series and create a new time series. Then we test the TY procedure to determine Granger causality in the new time series. We continue each iteration by excluding the first-day observations until, in the last iteration, we have only observations related to the last few days of our original time series.

We use the rolling horizon due to the variability and irregular structure of prediction market time series. The number of trades per day at the beginning of both prediction market time series (i.e., 14 months before the election date) are lower than that at the end because trading increases remarkably near the election date. Simultaneously, financial market time series are regular during market hours, with five-minute granularity. In other words, when we regularize a pair of time series, the limited number of changes at the beginning of prediction market time series may affect lag order selection and causality results. Moreover, Hacker and Hatemi-J (2006) show that the modified Wald (MWALD) test is sensitive to and performs poorly with small sample sizes. Thus, by excluding observations related to a specific day at the time-series beginning in each iteration, we remove those low-change areas, and by moving forward to the next iterations, we consider the different structures of time series in our analysis to reduce the risk of lag-order-selection errors.

As Figure 3 illustrates, the original series includes $t$ days, and the total number of observations is $T$. In the first iteration, the first subset has $t-1$ days, and the number of observations is $T-n_{1}$, where $n_{1}$ is the total number of observations in the first day, which we excluded from the original series. In the last iteration, the last subset has $t-m$ 
days, and the number of observations is $T-n_{m}$, where $n_{m}$ is the total number of observations from the first day to the $m^{t h}$ day of the selected time series. Here, $m$ is set to $t-1, t-5$ and $t-30$ based on time series granularity to avoid a low number of observations in the last subset.

FIGURE 3 Rolling Day subset selection strategy

Original series, $(t)$ days:

Nov -2008

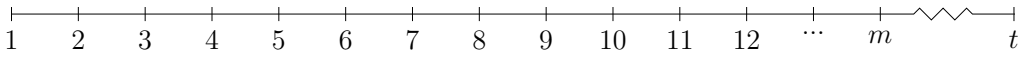

Rolling 1 day, $(t-1)$ days:

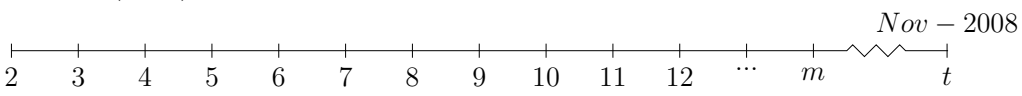

Rolling 2 days, $(t-2)$ days:

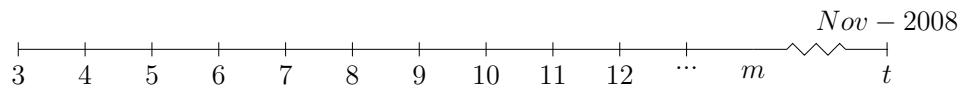

Rolling 3 days, $(t-3)$ days:

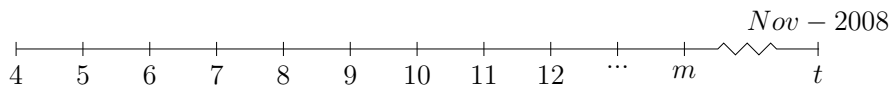

Rolling $\mathrm{m}$ days, $(t-m)$ days:

$$
\overbrace{m}^{N o v-2008}
$$

\subsection{2 | Moving Window Strategy}

With Moving Window, the second strategy to implement the TY procedure, we set the window widths to 3, 5, 10, 15,30 or 60 days. Then, for the first iteration, we start from the first day of the original time series and select those observations that are in the scope of the selected window. In each iteration, the TY process is tested on the selected observations. For the next iteration, we move our window forward by one day and test TY on the new window's observations. We continue to move our window forward to the end of the time series and we do the TY process on each iteration.

As Figure 4 shows, the original series includes $t$ days, and the total number of observations is $T$. Assume that we set the length of each moving window to 5 ; the first subset in the first iteration has 5 days and the number of observations is $n_{5,1}$, where $n_{5,1}$ is the total number of observations in the first 5 days of the original series, and the next iteration has $n_{5,2}$ observations. In the last iteration, the number of observations is $n_{5, t-5}$, which is the total number of observations from the last five days of the selected time series. 
FIGURE 4 Moving Window subset selection strategy

Original series, $(t)$ days:

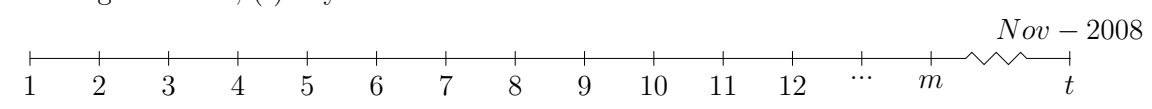

Subset 1, window width: (5) days

$\begin{array}{lllll} & 1 & \mid & \mid & \\ 1 & 2 & 3 & 4 & 5\end{array}$

Subset 2, window width: (5) days

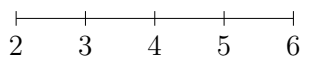

Subset 3, window width: (5) days

$\begin{array}{lllll} & & 1 & 1 & \\ 3 & 4 & 5 & 6 & 7\end{array}$

Subset t, window width: (5) days

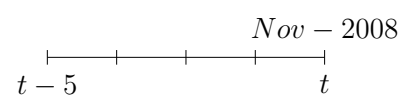

\section{6 | TY PROCEDURE RESULTS, CASE OF CANADA}

In this section, we show the results of TY procedure with two testing strategies in detail. With each strategy, we provide TY procedure results for the CADOWD-DEM2008 pair as a sample and then summarize the test results for the other pair, CADOWD-REP2008.

\section{1 | Rolling Day Strategy Results}

As an example, a pair, CADOWD and DEM2008, with 5 minute granularity has 475 days and 110125 observations; $m$ is set to $t-5$, and the number of subsets is 470 . Thus, we perform the TY process 470 times for the CADOWD-DEM2008 pair with the Rolling Day strategy. In this case, we choose CADOWD-D-M5-1 as a unique ID of the first iteration, in which $D$ stands for DEM2008, M5 stands for 5-minute granularity, and the numeral (1) shows the iteration ID.

Based on the TY procedure presented in Figure 2, to run the Granger causality test for CADOWD-D-M5-1, we start with the unit root test as the first step. In this case, the number of observations is 74,529 , and the maximum lag for the ADF test is 62 , calculated based on the equation (10). For the ADF test, we need to use a proper lag order, which is selected using the steps outlined in Section 5.1.1. In this research, for the ADF test, we use a lag order offered by $m A I C$ criterion which is equal to 1 for the CADOWD time series and 12 for the DEM2008 time series.

The null hypotheses of the ADF and PP say that there is a unit root present in the time series; on the other hand, the null hypothesis of KPSS says there is no unit root in the time series. According to the p-values, we cannot reject 
the null hypothesis of ADF and PP tests. In addition, the p-value of the KPSS test confirms that we can reject the null hypothesis. Thus, all three tests unanimously confirm the existence of a unit root in both series.

Based on our TY procedures, if we find a unit root in the time series, we need to transform the original time series, $I(0)$, by making a first difference to create a new time series, $I(1)$. Then, the results of ADF, PP and KPSS tests are consistent with one another indicating that both transformed time series are stationary.

By resolving the unit root problem of both time series, CADOWD and DEM2008, we conclude that the maximum order of integration, $d_{\max }$, is equal to one for the pair of CADOWD-DEM2008-M5-1.

After finding the value of $d_{\max }$, we need to the find optimal lag length, $k$, of the VAR model with the selected pair. First, we need to determine the model's lag length based on its information criteria. We set up a VAR model for the CADOWD-D-M5-1 series with the maximum lag of 62, calculated based on the equation (10), and we calculate the information criteria, $H Q(n)$ and $S C(n)$ which are 14 and 7 , respectively.

Since the reported $H Q(n)$ and $S C(n)$ are not equal, so based on the discussion in Section 5.1.2, we use the Likelihood Ratio test (LR Test) to decide which information criteria are appropriate for selecting the VAR model lag length. For the LR test, first, we set up two VAR models, VAR (lag=14) and VAR (lag=7), and then we calculate the log-likelihood of both, which are $736723.5(d f=32)$ and $736772.3(d f=60)$, respectively. In this case, when $H Q(n)<S C(n)$, the lag length of the restricted model is set to 7 and the unrestricted model to 14 , and the degree of freedom for the LR test is 60 . Finally, the test statistic of the LR test is 97.63 . If we then compare the LR test statistic with the chi-square critical value of 77.93 , calculated with a $95 \%$ significance level and 59 degrees of freedom, we conclude that the VAR lag length is equal to 14 , since the LR test statistic is less than the critical value. Thus, we need to take the unrestricted model lag, 14, as the appropriate lag length for the VAR model.

We set up a new VAR model with the selected lag length of 14. To ensure that the model has no serial correlation problem, we use a Breusch-Godfrey (BG) test with a 10 lag length. The p-value of the BG test is near zero $\left(2.111 \times 10^{-10}\right)$, so we cannot reject the null hypothesis of the existence of serial correlation, and we conclude that there is a serial correlation problem in our VAR model $\left(\chi^{2}=123.1729, d f=40\right)$.

If serial correlation is found in the VAR model, we need to increase the original lag order of the VAR model from 14 to 15 and set up a new model with a new lag order, 15, and again check for serial correlation. We must then repeat these steps, increasing the lag order each time, until we find a VAR model with no serial correlation problem. In our case, adding 9 lags to the original lag order creating a VAR model with 23 lags, thereby removing the serial correlation problem. The resulting BG's p-value is 0.2283 . We also confirm the non-existence of serial correlation in $\operatorname{VAR}(23)$ by using BG lag orders of $9,8,7,6,5$. Moreover, we make sure that the VAR model with the optimal lag, $\operatorname{VAR}(23)$, is stable. The stability test shows that both CADOWD and DEM2008 are stable, with root stabilities of 1.00002 and 1.000109 , respectively (both are greater than one). Thus, after investigating the serial correlation issue and stability of the VAR model, we can take the lag order of 23 as the VAR optimal lag order, $k$.

The significant coefficients in VAR(23) show that DEM2008.I13 (lag 13 of DEM2008) has the most-significant effect on CADOWD. Also, CADOWD.I2 (lag 2 of CADOWD) has the most-significant effect on DEM2008.

The coefficient of lag 13 of DEM2008 is 0.00747 , meaning that the prediction market has the most significant affect on the financial market, with 13 lags. In other words, since the time series has 5-minute intervals, those 13 lags are equal to 65 minutes; so we can say, therefore, that the Canadian financial market incorporates the U.S. prediction market data after about one hour. Moreover, since we use a logarithmic transformation of the time series, the coefficient of DEM2008.113 means that a 1 percent increase in DEM2008 results in a 0.00747 percent increase in CADOWD.

To understand the causality of this relationship, we use Wald testing. Wald test statistics for DEM2008 $\rightarrow$ CADOWD and CADOWD $\rightarrow$ DEM2008 are 33.974 and 33.374, respectively. The p-values related to both test statistics are 
0.066 and 0.075 , which are both greater than $0.05 \%$ and show that we can reject the null hypotheses, "DEM2008 does not Granger cause CADOWD" and "CADOWD does not Granger cause DEM2008". Thus, we conclude that there is a bilateral significant causal relationship between DEM2008 and CADOWD for the time series CADOWD-DEM2008M5-1.

As a final step, to confirm the results of this relationship, we need to make sure that there is no structural break in either the CADOWD or DEM2008 time series. For this purpose, we search for any structural break using a ZivotAndrew (ZA) test. The results of ZA testing show a possible structural break in the DEM2008 series, hence we must avoid claiming that the existent bilateral relationship is significant. Then, we conclude that there is no significant causal relationship when we consider the existence of structural break in CADOWD-DEM2008-M5-1.

As we continue the TY procedure for subsequent iterations, the ZA test might show different results for a possible structural break because in each iteration of the rolling day strategy we are omitting observations from the beginning of the time series and we may pass the break point.

We continue testing the TY procedure up to the last iteration, CADOWD-DEM2008-M5-452. The summery of 452 iterations of TY procedure shows that we do have more significant causal relationships at the end of iterations, when we approach approach the election date, which means that the prediction market starts to impact global financial market near election date more frequently. Also, by comparing the summary of CADOWD-REP2008-M5 iteration results, we can see that the REP2008 has more significant causal relation ship at the end, which implies that causal relationships between CADOWD and REP2008 are stronger than those between CADOWD and DEM2008 for the same two pairs of 5 -minute granularity time series.

We extend our testing process by generating new time series with different granularities described in Section 4.3. For example, Figure 5 shows the causality directions of $\mathrm{PM} \rightarrow \mathrm{SM}, \mathrm{SM} \rightarrow \mathrm{PM}, \mathrm{SM} \leftrightarrow \mathrm{PM}$, and "No Causality" for the pair CADOWD-REP2008. This figure has 11 bars, which are related to the time series of 5, 10, 15 and 30-minute granularities, and 1, 2, 4, 8, 12 and 16-hour granularities. The last bar is related to the daily time series.

In Figure 5, each bar shows the causality directions of a specific granularity. In each bar, blue shows the causality direction from DEM2008 to CADOWD (PM $\rightarrow$ SM), yellow shows causality direction from CADOWD to DEM2008 $(\mathrm{SM} \rightarrow \mathrm{PM})$, green, which is a mixture of blue and yellow, shows bilateral direction $(P M \leftrightarrow S M)$, and finally, red indicates no causality. The white gaps in each bar show that the TY procedure was not tested on those time series. The bars are not aligned on the right side of Figure 5, because iterations are stopped at different time points based on time series granularity, to make sure that we have enough observations to run TY procedures when approaching the election date. The white gaps in the middle of each bar are due to missing data for some specific dates, mostly holidays, which cause some iterations of the TY procedure to skip over those dates.

Table 1 summarizes the test results presented in Figure 5. Numbers in the middle of the table represent the percentage of significant causal relationships in the selected series, direction and granularity. In other words, this table shows the percentage of unique causal relationships for $\mathrm{PM} \rightarrow \mathrm{SM}$ and $\mathrm{SM} \rightarrow \mathrm{PM}$. The overlaps of significant causal relationships are shown in the "Both" direction, and the percentage of non-causality is shown in the "Non" row. For each Series, the numbers in each column sum to unity. For example, the first row of Table 1 shows that the Canadian financial market incorporated information on the Republican prediction market at 5-minute and 10-minute intervals, with $31 \%$ and $32 \%$ significant causal relationships, which is better than the results for other granularities. (Numbers are rounded to two decimal places)

Table 2 shows the coefficient means for $\mathrm{PM} \rightarrow \mathrm{SM}$ causal relationships for different granularities.

Tables 3 and 4 summarize the information presented in Tables 1 and 2. Table 3 shows the percentage of significant causalities averaged from the rows with 11 granularities represented in Table 1. Going forward, we refer to the numbers in Table 3 as the time invariant Expected Effect (EE) percentages. Based on the four mutually exclusive causal 
FIGURE 5 Causality direction of CADOWD-REP2008

Causality Direction Chart CADOWD-REP2008
$\mathrm{PM} \rightarrow \mathrm{SM} \quad \mathrm{PM} \leftrightarrow \mathrm{SM}$

$\mathrm{SM} \rightarrow \mathrm{PM} \perp$ No Causality

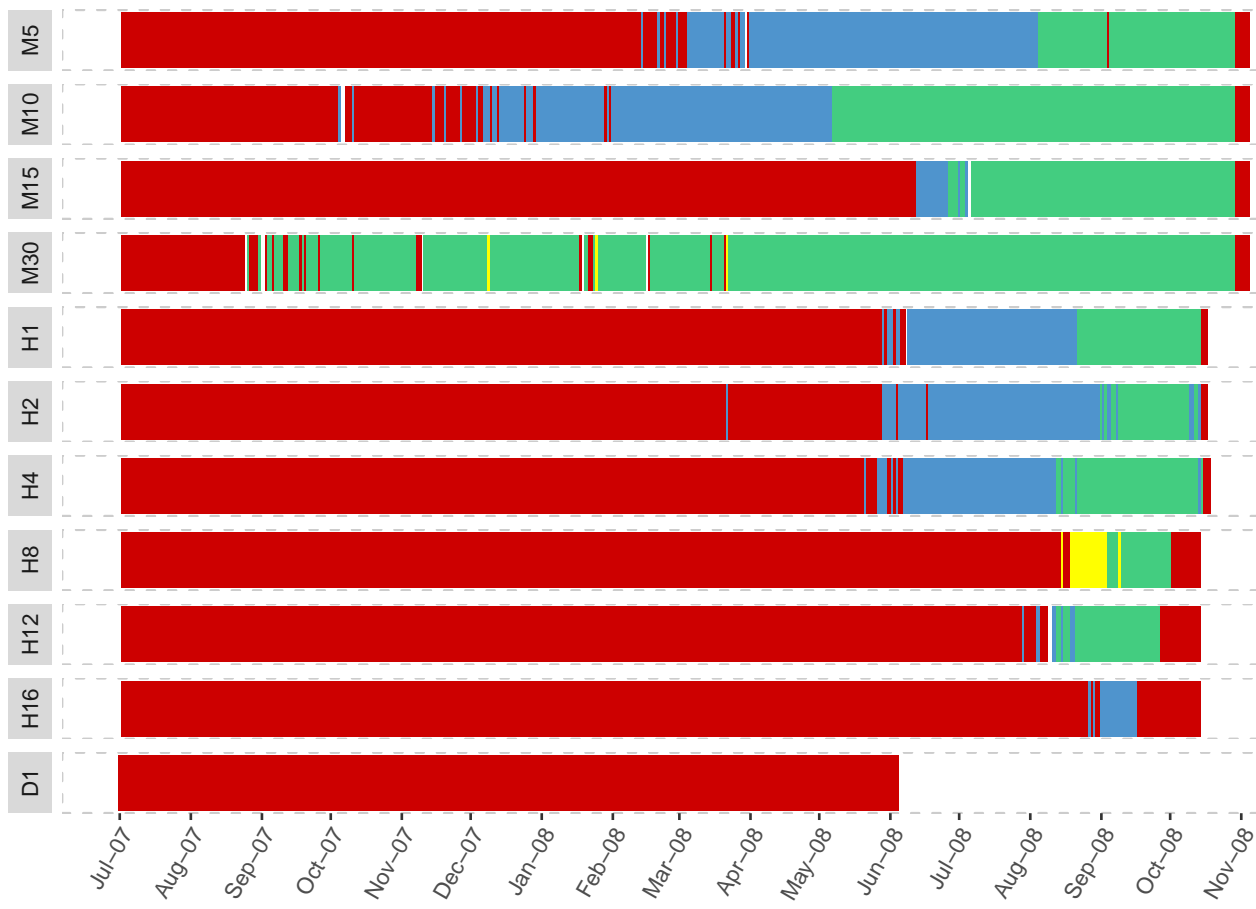

TAB LE 1 Percentage of significant causality for each direction (CADOWD-REP2008)

\begin{tabular}{l|ccccccccccc}
\hline Direction & $\mathrm{M} 5$ & $\mathrm{M} 10$ & $\mathrm{M} 15$ & $\mathrm{M} 30$ & $\mathrm{H} 1$ & $\mathrm{H} 2$ & $\mathrm{H} 4$ & $\mathrm{H} 8$ & $\mathrm{H} 12$ & $\mathrm{H} 16$ & $\mathrm{D} 1$ \\
\hline \hline $\mathrm{PM} \rightarrow \mathrm{SM}$ & 0.31 & 0.32 & 0.03 & 0.00 & 0.16 & 0.21 & 0.15 & 0.00 & 0.02 & 0.04 & 0.00 \\
$\mathrm{SM} \rightarrow \mathrm{PM}$ & 0.00 & 0.00 & 0.00 & 0.01 & 0.00 & 0.00 & 0.00 & 0.04 & 0.00 & 0.00 & 0.00 \\
\hline Both & 0.18 & 0.36 & 0.25 & 0.82 & 0.12 & 0.08 & 0.14 & 0.06 & 0.09 & 0.00 & 0.00 \\
Non & 0.52 & 0.32 & 0.72 & 0.17 & 0.72 & 0.71 & 0.71 & 0.90 & 0.88 & 0.96 & 1.00
\end{tabular}

TABLE 2 Coefficient's mean for PM $\rightarrow$ SM, CADOWD-REP2008

\begin{tabular}{c|ccccccccccc}
\hline & $\mathrm{M} 5$ & $\mathrm{M} 10$ & $\mathrm{M} 15$ & $\mathrm{M} 30$ & $\mathrm{H} 1$ & $\mathrm{H} 2$ & $\mathrm{H} 4$ & $\mathrm{H} 8$ & $\mathrm{H} 12$ & $\mathrm{H} 16$ & $\mathrm{D} 1$ \\
\hline \hline Mean & 0.0038 & -0.0002 & 0.0143 & 0.0000 & -0.0109 & 0.0035 & -0.0304 & 0.0 & 0.0238 & 0 & 0
\end{tabular}


relationships, described in the research hypothesis (section 3.1), the four Expected Effect percentages are defined as follows: Expected Lead Effect (ELE), Expected Follow Effect (EFE), Expected Feedback Effect (EBE) and Expected Neutral Effect (ENE) percentages.

TABLE 3 Rolling Day Expected Effect percentages

\begin{tabular}{l|cccc}
\hline Series Name & $\begin{array}{c}\mathrm{PM} \rightarrow \mathrm{SM} \\
\text { ELE Percentage }\end{array}$ & $\begin{array}{c}\mathrm{SM} \rightarrow \mathrm{PM} \\
\mathrm{EFE} \text { Percentage }\end{array}$ & $\begin{array}{c}\text { Both } \\
\text { EBE Percentage }\end{array}$ & $\begin{array}{c}\text { Non } \\
\text { ENE Percentage }\end{array}$ \\
\hline \hline CADOWD-DEM2008 & 0.005 & 0.127 & 0.176 & 0.692 \\
\hline CADOWD-REP2008 & 0.113 & 0.005 & 0.192 & 0.690 \\
\hline
\end{tabular}

Table 4 shows the sum-products of EE (Table 1) and their relevant significant causal relationship coefficient means (Table 2) with 11 granularities. The numbers in Table 4 represent the Expected Effect magnitudes, which have four possible categories depending on whether they indicate Lead, Follow, Feedback or Neutral causal directions.

TABLE 4 Rolling Day Expected Effect magnitudes

\begin{tabular}{l|cccc}
\hline Series Name & $\begin{array}{c}\mathrm{PM} \rightarrow \mathrm{SM} \\
\text { ELE Magnitude }\end{array}$ & $\begin{array}{c}\mathrm{SM} \rightarrow \mathrm{PM} \\
\text { EFE Magnitude }\end{array}$ & $\begin{array}{c}\text { Both } \\
\text { EBE Magnitude }\end{array}$ & $\begin{array}{c}\text { Non } \\
\text { ENE Magnitude }\end{array}$ \\
\hline \hline CADOWD-DEM2008 & -0.002 & -0.158 & -0.061 & -0.235 \\
\hline CADOWD-REP2008 & -0.004 & -0.004 & -0.006 & 0.171 \\
\hline
\end{tabular}

We discuss the implications of this section and Section 6.2 together in Section 6.2.

\section{2 | Moving Window strategy results}

With the Moving Window strategy, we again perform the TY process 470 times for the CADOWD-DEM2008 pair, using a window width of 5 days. We have selected the window widths based on time series granularity. Time series with finer granularities are tested with smaller window widths and series with coarser granularities are tested with larger window widths. For example, a 5-minute (M5) time series is tested with four different windows, which are 3, 5, 10 and 15 days. Table 5 shows the window widths for different granularities.

We have repeated the Moving Window strategy with the various window widths listed in Table 5. Tables 6 and 7 summarize the percentage of significant causal relationships (Expected Effect percentages) and the sum-products of Expected Effect with the relevant coefficients (Expected Effect magnitudes) for the pair CADOWD-DEM2008 in the four directions for all window widths.

Table 8 shows the average of each direction over all windows (columns in Table 6). Similar to the results of Rolling Day strategy, the first data column, $\mathrm{PM} \rightarrow \mathrm{SM}$, shows that the probability of the Republicans winning rather than the Democrats has more causality effect on the Canadian financial market under Moving Window strategy.

Table 10 shows the ELE percentages and magnitudes presented in Tables 3, 4, 8 and 9, related to the CADOWD series for both strategies.

Comparing the ELE for the two parties shows that, under both strategies, the percentages and magnitude of the Republican's ELEs are greater than the Democrat's (REP2008 $\rightarrow$ SM). Thus, we conclude that the Canadian financial 
TAB LE 5 Moving Window widths based on time series granularity

\begin{tabular}{l|ccccccccccc}
\hline Window & M5 & M10 & M15 & M30 & H1 & H2 & H4 & H8 & H12 & H16 & D1 \\
\hline \hline 3 Days & $\checkmark$ & - & - & - & - & - & - & - & - & - & - \\
5 Days & $\checkmark$ & $\checkmark$ & $\checkmark$ & - & - & - & - & - & - & - & - \\
10 Days & $\checkmark$ & $\checkmark$ & $\checkmark$ & $\checkmark$ & $\checkmark$ & $\checkmark$ & - & - & - & - & - \\
15 Days & $\checkmark$ & $\checkmark$ & $\checkmark$ & $\checkmark$ & $\checkmark$ & $\checkmark$ & $\checkmark$ & $\checkmark$ & $\checkmark$ & - & - \\
30 Days & - & - & - & - & - & - & $\checkmark$ & $\checkmark$ & $\checkmark$ & $\checkmark$ & - \\
60 Days & - & - & - & - & - & - & - & - & - & $\checkmark$ & $\checkmark$ \\
\hline
\end{tabular}

TAB LE 6 Window Strategy Expected Effect percentages, all granularities

\begin{tabular}{l|cccc}
\hline $\begin{array}{l}\text { CADOWD-DEM2008 } \\
\text { Window }\end{array}$ & $\begin{array}{c}\mathrm{PM} \rightarrow \mathrm{SM} \\
\text { ELE Percentage }\end{array}$ & $\begin{array}{c}\mathrm{SM} \rightarrow \mathrm{PM} \\
\text { EFE Percentage }\end{array}$ & $\begin{array}{c}\text { Both } \\
\text { EBE Percentage }\end{array}$ & $\begin{array}{c}\text { Non } \\
\text { ENE Percentage }\end{array}$ \\
\hline \hline 3 & 0.020 & 0.018 & 0.089 & 0.873 \\
\hline 5 & 0.029 & 0.028 & 0.135 & 0.809 \\
\hline 10 & 0.028 & 0.041 & 0.217 & 0.713 \\
\hline 15 & 0.028 & 0.040 & 0.245 & 0.687 \\
\hline 30 & 0.041 & 0.040 & 0.311 & 0.608 \\
\hline 60 & 0.008 & 0.026 & 0.378 & 0.588 \\
\hline
\end{tabular}

TAB LE 7 Window Strategy Expected Effect magnitudes, all granularities

\begin{tabular}{l|cccc}
\hline $\begin{array}{l}\text { CADOWD-DEM2008 } \\
\text { Window }\end{array}$ & $\begin{array}{c}\mathrm{PM} \rightarrow \mathrm{SM} \\
\text { ELE Magnitude }\end{array}$ & $\begin{array}{c}\mathrm{SM} \rightarrow \mathrm{PM} \\
\mathrm{EFE} \text { Magnitude }\end{array}$ & $\begin{array}{c}\text { Both } \\
\text { EBE Magnitude }\end{array}$ & $\begin{array}{c}\text { Non } \\
\text { ENE Magnitude }\end{array}$ \\
\hline \hline 3 & -0.0005 & -0.0048 & 0.0000 & 0.0033 \\
\hline 5 & 0.0026 & -0.0168 & -0.0003 & -0.0655 \\
\hline 10 & -0.0028 & -0.0279 & -0.0063 & -0.0840 \\
\hline 15 & -0.0048 & -0.0594 & -0.0106 & -0.0629 \\
\hline 30 & -0.0023 & -0.0049 & -0.0025 & -0.0061 \\
\hline 60 & -0.0019 & 0.0015 & 0.0002 & -0.0015 \\
\hline
\end{tabular}

market tends to incorporate the probability of the Republicans winning, and the probability of the Republicans winning tends to have a causal effect on the Canadian financial market more frequently and strongly. In the next section we move to discuss our results from applying our analysis to all 27 regions and countries. 
TABLE 8 Window Strategy Expected Effect percentages, all windows, all granularities

\begin{tabular}{l|cccc}
\hline Series & $\begin{array}{c}\mathrm{PM} \rightarrow \mathrm{SM} \\
\text { ELE Percentage }\end{array}$ & $\begin{array}{c}\mathrm{SM} \rightarrow \mathrm{PM} \\
\mathrm{EFE} \text { Percentage }\end{array}$ & $\begin{array}{c}\text { Both } \\
\text { EBE Percentage }\end{array}$ & $\begin{array}{c}\text { ENE } \\
\text { ENE Percentage }\end{array}$ \\
\hline \hline CADOWD-DEM2008 & 0.026 & 0.032 & 0.229 & 0.713 \\
\hline CADOWD-REP2008 & 0.058 & 0.033 & 0.192 & 0.718 \\
\hline
\end{tabular}

TAB LE 9 Window Strategy Coefficient Effects, all windows, all granularities

\begin{tabular}{|c|c|c|c|c|}
\hline Series Name & $\begin{array}{c}\mathrm{PM} \rightarrow \mathrm{SM} \\
\text { ELE Magnitude }\end{array}$ & $\begin{array}{c}\mathrm{SM} \rightarrow \mathrm{PM} \\
\text { EFE Magnitude }\end{array}$ & $\begin{array}{l}\text { Both } \\
\text { EBE Magnitude }\end{array}$ & $\begin{array}{c}\text { Non } \\
\text { ENE Magnitude }\end{array}$ \\
\hline CADOWD-DEM2008 & -0.0016 & -0.0187 & -0.0032 & -0.0361 \\
\hline CADOWD-REP2008 & 0.0006 & 0.0001 & -0.0029 & 0.0039 \\
\hline
\end{tabular}

TAB LE 10 Expected Lead Effect (ELE) percentages and magnitudes, both strategies

\begin{tabular}{|c|c|c|c|c|}
\hline $\begin{array}{l}\text { Series Name } \\
\text { CADOWD }\end{array}$ & $\begin{array}{l}\text { DEM2008 } \rightarrow \text { SM } \\
\text { ELE Percentage }\end{array}$ & $\begin{array}{l}\text { REP2008 } \rightarrow \mathrm{SM} \\
\text { ELE Percentage }\end{array}$ & $\begin{array}{l}\text { DEM2008 } \rightarrow \text { SM } \\
\text { ELE Magnitude }\end{array}$ & $\begin{array}{l}\text { REP2008 } \rightarrow \text { SM } \\
\text { ELE Magnitude }\end{array}$ \\
\hline Rolling Day Strategy & 0.5 & 11.3 & -0.002 & -0.004 \\
\hline Window Strategy & 2.6 & 5.8 & -0.0016 & 0.0006 \\
\hline
\end{tabular}

\section{7 | RESULTS AND DISCUSSION}

In the various tables and graphs, presented in the last section, we show the TY procedure tests results for the Canadian market, pairs CADOWD-DEM2008 and CADOWD-REP2008, at different granularities. We conclude that the probability of the Republicans winning rather than the Democratics had more significant causal effects on the Canadian financial market than the reverse would have.

We extend the TY procedure testing for the other 26 financial markets. Tables 11 and 12 show the result of Rolling Day and Moving Window strategies tested for pairs of the two prediction markets' data and the 27 global financial markets time series, including Canada. By comparing ELE magnitudes, the last two columns of Tables 11 and 12, we determined which party had more effect on the selected financial markets (in both tables the greater Expected Lead Effect value is indicated by $\uparrow$ in each row).

To investigate whether the global financial markets are informationally efficient with reference to the U.S. election outcome, we can evaluate the existence, magnitude and direction of causal relationships. If there is no considerable Lead Effect $(\mathrm{PM} \rightarrow \mathrm{SM})$, we conclude that the financial market is efficient. 
TAB LE 11 Rolling Day strategy, Expected Lead Effect (ELE) percentages and magnitudes (actual values)

\begin{tabular}{|l|cc|cc}
\hline Countries/Regions Name & $\begin{array}{c}\text { DEM } 2008 \rightarrow \text { SM } \\
\text { ELE Percentage }\end{array}$ & $\begin{array}{c}\text { REP2008 } \rightarrow \text { SM } \\
\text { ELE Percentage }\end{array}$ & $\begin{array}{c}\text { DEM2008 } \rightarrow \text { SM } \\
\text { ELE Magnitude }\end{array}$ & $\begin{array}{c}\text { REP2008 } \rightarrow \text { SM } \\
\text { Magnitude }\end{array}$ \\
\hline \hline Americas (A1DOW) & 1.3 & $13 \uparrow$ & -0.001 & $-0.002 \uparrow$ \\
\hline Latin America (A3DOW) & 2.9 & $7.6 \uparrow$ & 0.009 & $0.037 \uparrow$ \\
\hline Latin America ex-Mex (A4DOW) & 1.6 & $6 \uparrow$ & -0.004 & $0.048 \uparrow$ \\
\hline Austria (ATDOWD) & 1.8 & $3 \uparrow$ & $-0.025 \uparrow$ & 0.018 \\
\hline Australia (AUDOWD) & 7.8 & $13.2 \uparrow$ & -0.007 & $0.034 \uparrow$ \\
\hline Belgium (BEDOWD) & $9.8 \uparrow$ & 7.5 & -0.001 & $-0.02 \uparrow$ \\
\hline Brazil (BRDOWD) & 1.6 & $9.7 \uparrow$ & 0.009 & $-0.016 \uparrow$ \\
\hline Canada (CADOWD) & 0.5 & $11.3 \uparrow$ & -0.002 & $-0.004 \uparrow$ \\
\hline Germany (DEDOWD) & $5.9 \uparrow$ & 1.2 & $-0.013 \uparrow$ & -0.006 \\
\hline Denmark (DKDOWD) & $7.4 \uparrow$ & 2.9 & 0.003 & $-0.008 \uparrow$ \\
\hline Europe (E1DOW) & $11 \uparrow$ & 5.4 & 0.002 & $0.023 \uparrow$ \\
\hline Europe ex-U.K. (E2DOW) & $8.7 \uparrow$ & 4.2 & 0.001 & $0.018 \uparrow$ \\
\hline Europe - Nordic (E3DOW) & $8.4 \uparrow$ & 3.7 & $-0.036 \uparrow$ & 0.014 \\
\hline Finland (FIDOWD) & $9.5 \uparrow$ & 4.6 & $-0.045 \uparrow$ & 0.019 \\
\hline France (FRDOWD) & $10.8 \uparrow$ & 3.1 & -0.001 & $-0.011 \uparrow$ \\
\hline Greece (GRDOWD) & 2.4 & $3.5 \uparrow$ & 0 & $0.003 \uparrow$ \\
\hline Hong Kong (HKDOWD) & $3.9 \uparrow$ & 2.7 & -0.001 & $0.005 \uparrow$ \\
\hline Indonesia (IDDOWD) & 0 & $2.1 \uparrow$ & 0 & $0.015 \uparrow$ \\
\hline Ireland (IEDOWD) & $6.6 \uparrow$ & $6.6 \uparrow$ & -0.006 & $-0.071 \uparrow$ \\
\hline Italy (ITDOWD) & $8.2 \uparrow$ & 6.8 & 0.002 & $0.055 \uparrow$ \\
\hline Japan (JPDOWD) & 3.2 & $6.2 \uparrow$ & 0 & $-0.002 \uparrow$ \\
\hline Mexico (MXDOWD) & 1.5 & $3.1 \uparrow$ & 0.001 & $-0.017 \uparrow$ \\
\hline Malaysia (MYDOWD) & 0.9 & $23.9 \uparrow$ & 0 & $0.013 \uparrow$ \\
\hline Netherlands (NLDOWD) & $11.2 \uparrow$ & 6 & $-0.012 \uparrow$ & -0.009 \\
\hline Norway (NODOWD) & $3.6 \uparrow$ & 2.9 & $-0.166 \uparrow$ & 0.005 \\
\hline Zealand (NZDOWD) & 1.4 & $5.2 \uparrow$ & 0.001 & $0.014 \uparrow$ \\
\hline
\end{tabular}

Comparing the behaviour of each of the 27 financial markets under the two testing strategies (using results shown in Tables 11 and 12), in most cases shows that the two strategies identify the same prediction market as most likely to affect a financial market. For example, the Canadian financial market, CADOWD, was affected by the probability 
TAB LE 12 Moving Window strategy, Expected Lead Effect (ELE) percentages and magnitudes

\begin{tabular}{|c|c|c|c|c|}
\hline Series Name & $\begin{array}{l}\text { DEM2008 } \rightarrow \text { SM } \\
\text { ELE Percentage }\end{array}$ & $\begin{array}{l}\text { REP2008 } \rightarrow \text { SM } \\
\text { ELE Percentage }\end{array}$ & $\begin{array}{l}\text { DEM2008 } \rightarrow \text { SM } \\
\text { ELE Magnitude }\end{array}$ & $\begin{array}{c}\text { REP2008 } \rightarrow \text { SM } \\
\text { Magnitude }\end{array}$ \\
\hline Americas (A1DOW) & 2.9 & $4 \uparrow$ & $-0.0001 \uparrow$ & $-0.0001 \uparrow$ \\
\hline Latin America (A3DOW) & 2.9 & $5.7 \uparrow$ & $0.0001 \uparrow$ & $-0.0001 \uparrow$ \\
\hline Latin America ex-Mex (A4DOW) & $3.9 \uparrow$ & 3.8 & $0 \uparrow$ & $0 \uparrow$ \\
\hline Austria (ATDOWD) & 2.6 & $2.8 \uparrow$ & $0.0003 \uparrow$ & 0 \\
\hline Australia (AUDOWD) & $3.2 \uparrow$ & 2.8 & $0.0036 \uparrow$ & 0.0002 \\
\hline Belgium (BEDOWD) & 2.6 & $3.2 \uparrow$ & $0 \uparrow$ & $0 \uparrow$ \\
\hline Brazil (BRDOWD) & 3.7 & $4.1 \uparrow$ & $-0.0013 \uparrow$ & 0 \\
\hline Canada (CADOWD) & 2.6 & $5.8 \uparrow$ & -0.0005 & $0.0033 \uparrow$ \\
\hline Germany (DEDOWD) & $3.5 \uparrow$ & $3.5 \uparrow$ & $0.0007 \uparrow$ & 0 \\
\hline Denmark (DKDOWD) & 1.9 & $3.3 \uparrow$ & $-0.0003 \uparrow$ & 0 \\
\hline Europe (E1DOW) & 3 & $3.6 \uparrow$ & $0 \uparrow$ & $0 \uparrow$ \\
\hline Europe ex-U.K. (E2DOW) & 3.1 & $3.7 \uparrow$ & $0.0012 \uparrow$ & 0 \\
\hline Europe - Nordic (E3DOW) & 3.7 & $4.1 \uparrow$ & $0 \uparrow$ & $0 \uparrow$ \\
\hline Finland (FIDOWD) & $3.2 \uparrow$ & 2.7 & $0 \uparrow$ & $0 \uparrow$ \\
\hline France (FRDOWD) & $3.5 \uparrow$ & 2.7 & $0 \uparrow$ & $0 \uparrow$ \\
\hline Greece (GRDOWD) & $3.3 \uparrow$ & 2.8 & 0 & $0.0001 \uparrow$ \\
\hline Hong Kong (HKDOWD) & $2.1 \uparrow$ & 1.7 & $-0.0011 \uparrow$ & 0 \\
\hline Indonesia (IDDOWD) & 1.5 & $3.7 \uparrow$ & $0 \uparrow$ & $0 \uparrow$ \\
\hline Ireland (IEDOWD) & 1.7 & $2.8 \uparrow$ & $0 \uparrow$ & $0 \uparrow$ \\
\hline Italy (ITDOWD) & 2.7 & $2.8 \uparrow$ & $-0.0045 \uparrow$ & 0 \\
\hline Japan (JPDOWD) & $1.7 \uparrow$ & 1.5 & $0 \uparrow$ & $0 \uparrow$ \\
\hline Mexico (MXDOWD) & 3.3 & $5.5 \uparrow$ & $0.0011 \uparrow$ & -0.0007 \\
\hline Malaysia (MYDOWD) & 2.7 & $3.2 \uparrow$ & $-0.0033 \uparrow$ & 0 \\
\hline Netherlands (NLDOWD) & 3.3 & $3.7 \uparrow$ & $0.0004 \uparrow$ & 0.0002 \\
\hline Norway (NODOWD) & 2.9 & $3.2 \uparrow$ & 0 & $-0.0001 \uparrow$ \\
\hline New Zealand (NZDOWD) & 2.2 & $2.9 \uparrow$ & $0.0004 \uparrow$ & -0.0001 \\
\hline China (DJCHINA) & $1.6 \uparrow$ & 1.1 & $0 \uparrow$ & $0 \uparrow$ \\
\hline
\end{tabular}

of the Republican party winning under both strategies, and the Expected Lead Effect percentage (ELE percentage) of Rolling Day strategy, $11.3 \%$, is greater than the ELE percentage of the Moving Window strategy, $5.82 \%$. Thus, the Canadian financial market tends to respond to the U.S. election outcome in longer rather than shorter time horizons. 
Tables 11 and 12 show that the average ELE percentages of the 27 countries or regions are $3.49 \%$ and $8.14 \%$ for the Moving Window and Rolling Day strategies, respectively. Under Moving Window strategy, most of the ELE percentages are less than $5 \%$ (average $3.49 \%$ ), which implies short-term financial-market efficiency.

In almost all cases, except Mexico and Indonesia, the ELE percentages of the Rolling Day strategy are much greater than the ELE percentages of the Moving Window strategy. This fact generally implies that the financial markets tend to incorporate the U.S. election outcome in the long term. On the other hand, Mexico and Indonesia's financial markets tend to incorporate the U.S. election outcome in the short term. However, under the Moving Window, the ELE magnitudes of Mexico and Indonesia are smaller than the Rolling Day ELE magnitudes.

Considering long-term effects under the Rolling Day strategy, the ELE percentages of all three European indices -E1DOW, E2DOW and E3DOW- confirm that the European markets are frequently influenced by Democratic party wins, however, the ELE magnitudes of all three European indices show that the Republican party had a more powerful effect. Thus, we conclude that European markets are not highly efficient in respect to the U.S. election outcome (ELE percentages average $9.36 \%$ ).

Also, regarding all three Americas' (North, South and Central) indices -A1DOW, A3DOW and A4DOW- the results show that North and South American countries' financial markets are more likely to be influenced by the Republican party than are central ones. Moreover, Americas' ELE percentages average $8.8 \%$, showing that financial markets are not highly efficient in any of the Americas regarding U.S. presidential election information.

\section{8 | CONCLUSIONS}

The primary objective of this research was to investigate the existence and direction of causality relationships between the U.S. presidential election outcome and various global financial markets. For this purpose, we have implemented the Toda-Yamamoto causality test to overcome the pitfalls of conventional Granger causality testing. We estimated VAR models with additional lags, and choose a modified version of Wald testing to ensure asymptotic $\chi^{2}$ distribution.

This research has taken two different strategies for estimating VAR models: Rolling Day and Moving Window. The first considers longer time horizons, tested in multiple iterations, and the second examines shorter time horizons. Using two strategies allowed us to investigate the Efficient Market Hypothesis (EMH) through two different lenses.

In almost all cases, the ELE magnitudes of both Rolling Day and Moving Window strategies show that the Republicans had more powerful effects on financial markets.

The semi-strong form of EMH, in this research, implies that changes in financial-market prices are independent from changes in the probability of a certain party winning the U.S. election. In other words, financial market prices incorporate all publicly available information, including that related to a U.S. election outcome.

Financial markets can be divided into three main categories: highly efficient, efficient, and moderately efficient. The Rolling Day results show that, in the longer term, some countries such as Austria, Greece, Hong Kong, Indonesia, Mexico and Norway are highly efficient since their Expected Lead Effect percentages are less than $5 \%$. Countries or regions such as Latin America, Latin America ex-Mex, Belgium, Brazil, Germany, China, Denmark, Europe ex-UK, Europe-Nordic, Finland, Ireland, Italy, Japan and New Zealand are efficient since their Expected Lead Effect percentages are between 5\% and 10\%. Finally, with Expected Lead Effect percentages greater than 10\%, countries or regions such as the Americas, Australia, Canada, Europe, France, Malaysia and the Netherlands are moderately efficient. 


\section{Data Availability Statement}

The prediction market data that support the findings of this study are openly available in Github repository at the following URL: https://github.com/ipeirotis/Intrade-Archive. Also, the global financial market data (DJGIs indecies) that support the findings of this study are available from Kibot data. Restrictions apply to the availability of these data, which were used under license for this study. Data are available at http://www.kibot.com/ with the permission of Kibot data.

\section{references}

Akaike, H. (1973) Information theory and an extension of the maximum likelihood principle. In Second International Symposium on Information Theory (eds. B. N. Petrov and F. Csaki), 267-281. Budapest: Akadémiai Kiado.

Aktas, H. and Oncu, S. (2006) The stock market reaction to extreme events: the evidence from turkey. International Research Journal of Finance and Economics, 6, 78-85.

Alesina, A. and Perotti, R. (1996) Budget deficits and budget institutions. Tech. rep., National Bureau of Economic Research.

Alesina, A. and Rosenthal, H. (1995) Partisan politics, divided government, and the economy. Cambridge University Press.

Alesina, A. and Roubini, N. (1992) Political Cycles in OECD Economies. Source: The Review of Economic Studies, 59, 663-688.

Alesina, A. F. and Sachs, J. D. (1986) Political parties and the business cycle in the united states, 1948-1984.

Allvine, F. C. and O'Neill, D. E. (1980) Stock market returns and the presidential election cycle: Implications for market efficiency. Financial Analysts Journal, 36, 49-56.

Arora, V. and Vamvakidis, A. (2004) The impact of us economic growth on the rest of the world: How much does it matter? Journal of Economic Integration, 1-18.

Aylward, A. and Glen, J. (2000) Some international evidence on stock prices as leading indicators of economic activity. Applied Financial Economics, 10, 1-14.

Baker, S. R., Bloom, N. and Davis, S. J. (2016) Measuring economic policy uncertainty. The quarterly journal of economics, 131, 1593-1636.

Balvers, R. J., Cosimano, T. F. and McDonald, B. (1990) Predicting stock returns in an efficient market. The Journal of Finance, 45, 1109-1128.

Bartels, L. M. (1988) Presidential primaries and the dynamics of public choice. Princeton University Press.

Bawn, K. and Rosenbluth, F. (2006) Short versus long coalitions: electoral accountability and the size of the public sector. American Journal of Political Science, 50, 251-265.

Berg, J., Nelson, F. and Rietz, T. (2003) Accuracy and forecast standard error of prediction markets. Tippie College of Business Administration, University of lowa.

Berg, J. E., Nelson, F. D. and Rietz, T. A. (2008) Prediction market accuracy in the long run. International Journal of Forecasting, 24, 285-300.

Berg, J. E. and Rietz, T. A. (2003) Prediction markets as decision support systems. Information systems frontiers, 5, 79-93.

Białkowski, J., Gottschalk, K. and Wisniewski, T. P. (2008) Stock market volatility around national elections. Journal of Banking \& Finance, 32, 1941-1953. 
Bittlingmayer, G. (1998) Output, stock volatility, and political uncertainty in a natural experiment: Germany, 1880-1940. The Journal of Finance, 53, 2243-2257.

Borge, A. (2015) 6 factors shaping the global economy in 2016. https://www . weforum.org/agenda/2015/12/6-factorsshaping-the-global-economy-in-2016/. (Accessed on 09/27/2018).

Borges, M. R. (2010) Efficient market hypothesis in european stock markets. The European Journal of Finance, 16, 711-726.

Breen, W., Glosten, L. R. and Jagannathan, R. (1989) Economic significance of predictable variations in stock index returns. The Journal of Finance, 44, 1177-1189.

Breusch, T. S. (1978) Testing for autocorrelation in dynamic linear models*. Australian Economic Papers, 17, $334-355$.

Brown, K. C., Harlow, W. and Tinic, S. M. (1988) Risk aversion, uncertain information, and market efficiency. Journal of Financial Economics, 22, 355-385. URL: https : //faculty.mccombs .utexas .edu/keith. brown/Research/JFE- 12.88.pdf.

Brüggelambert, G. (2004) Information and efficiency in political stock markets: using computerized markets to predict election results. Applied Economics, 36, 753-768.

Cahan, J., Malone, C. B., Powell, J. G. and Choti, U. W. (2005) Stock market political cycles in a small, two-party democracy. Applied Economics Letters, 12, 735-740.

Carlsen, F. (2000) Unemployment, inflation and government popularity-are there partisan effects? Electoral Studies, 19, 141-150.

Chiu, C.-L., Chen*, C.-D. and Tang, W.-W. (2005) Political elections and foreign investor trading in south korea's financial markets. Applied Economics Letters, 12, 673-677.

Colombo, V. (2013) Economic policy uncertainty in the us: Does it matter for the euro area? Economics Letters, 121, 39-42.

Comincioli, B. (1996) The stock market as a leading indicator: An application of granger causality. University avenue undergraduate journal of economics, $1,1$.

Cooray, A. and Wickremasinghe, G. (2007) The efficiency of emerging stock markets: Empirical evidence from the south asian region. The Journal of Developing Areas, 171-183.

Davidson, R. and MacKinnon, J. G. (2004) Instructor's Manual to Accompany Econometric Theory and Methods. Oxford University Press.

Davis, S. J. (2016) An index of global economic policy uncertainty. Tech. rep., National Bureau of Economic Research.

De Haan, J. and Sturm, J.-E. (1994) Political and institutional determinants of fiscal policy in the european community. Public choice, 80, 157-172.

DeBondt, W. F. M. and Thaler, R. H. (1985) Does the Stock Market Overreact? Journal of Finance, 40, 793-805.

Dickey, D. A. and Fuller, W. A. (1979) Distribution of the Estimators for Autoregressive Time Series With a Unit Root. Journal of the American Statistical Association, 74, 427-431.

Döpke, J. and Pierdzioch, C. (2006) Politics and the stock market: Evidence from germany. European Journal of Political Economy, 22, 925-943.

Dufour, J.-M. and Renault, E. (1998) Short run and long run causality in time series: theory. Econometrica, 1099-1125.

Engle, R. F. and Granger, C. W. J. (1987) Co-integration and Error Correction: Representation, Estimation, and Testing. Econometrica, 55, 251-76. 
Erikson, R. S. (1989) Economic Conditions and The Presidential Vote. American Political Science Review, 83, $567-573$.

Fair, R. (1978) The Effects of Economic Events on Votes for Presidents. Review of Economics and Statistics, 60, $159-172$.

Fama, E. (1991) Efficient markets: li, fiftieth anniversary invited paper. Journal of Finance, 46, 1575-1617.

Fama, E. F. and Malkiel, B. G. (1970) Efficient capital markets: A review of theory and empirical work. The journal of Finance, 25, 383-417.

Ferson, W. E. and Harvey, C. R. (1993) The risk and predictability of international equity returns. Review of financial Studies, 6 , 527-566.

Fiorina, M. P. (1991) Elections and the economy in the 1980s: Short-and long-term effects. In Politics and Economics in the Eighties, 17-40. University of Chicago Press.

Foerster, S. R. (1993) Stock market performance and elections: made-in-canada effects? Papers in Political Economy.

Foerster, S. R. and Schmitz, J. J. (1997) The transmission of us election cycles to international stock returns. Journal of International Business Studies, 28, 1-13.

Furió, D. and Pardo, Á. (2012) Partisan politics theory and stock market performance: Evidence for spain. Spanish Journal of Finance and Accounting/Revista Española de Financiación y Contabilidad, 41, 371-392.

Füss, R. and Bechtel, M. M. (2008) Partisan politics and stock market performance: The effect of expected government partisanship on stock returns in the 2002 german federal election. Public Choice, 135, 131-150.

Gemmill, G. (1992) Political risk and market efficiency: tests based in british stock and options markets in the 1987 election. Journal of Banking \& Finance, 16, 211-231.

Godfrey, L. G. (1978) Testing against general autoregressive and moving average error models when the regressors include lagged dependent variables. Econometrica: Journal of the Econometric Society, 1293-1301.

Gonzalo, J. and Pitarakis, J.-y. (2002) Lag length estimation in large dimensional systems. Journal of Time Series Analysis, 23, 401-423.

Granger, C. W. (1969) Investigating causal relations by econometric models and cross-spectral methods. Econometrica: Journal of the Econometric Society, 424-438.

Gujarati, D. N. and Porter, D. C. (2003) Basic econometrics. 4th. New York: McGraw-Hill.

- (2009) Essentials of econometrics.

Gümüş, B. F. and Zeren, F. (2014) Analyzing the efficient market hypothesis with the fourier unit root tests: Evidence from g-20 countries. Ekonomski horizonti, 16, 225-237.

Hacker, R. S. and Hatemi-J, A. (2006) Tests for causality between integrated variables using asymptotic and bootstrap distributions: theory and application. Applied Economics, 38, 1489-1500.

Hannan, E. J. and Quinn, B. G. (1979) The Determination of the Order of an Autoregression. Source Journal of the Royal Statistical Society. Series B (Methodological) Journal of the Royal Statistical Society. Series BMethodological) J. R. Statist. Soc. B, 41, 190-195.

Harvey, C. R. (1989) Forecasts of economic growth from the bond and stock markets. Financial Analysts Journal, 45, 38-45.

Hatemi-J, A. and S. Hacker, R. (2009) Can the Ir test be helpful in choosing the optimal lag order in the var model when information criteria suggest different lag orders? Applied Economics, 41, 1121-1125. 
Herron, M. C., Lavin, J., Cram, D. and Silver, J. (1999) Measurement of political effects in the United States economy: a study of the 1992 presidential election. Economics and Politics, 44.

Hibbs, D. (1977a) Political Parties and Macroeconomic Policy. American Political Science Review, 71, 1467-1487.

- (1987) The american political economy: Electoral policy and macroeconomics in contemporary america. Cambridge, MA: Harvard University.[Links].

Hibbs, D., Carlsen, F. and Pedersen, E. (1996) Electoral uncertainty and partisan output cycles. Research Training Group on Positive Political Economy, Harvard University.

Hibbs, D. A. (1977b) Political parties and macroeconomic policy. American political science review, 71, 1467-1487.

Ho, T.-H. and Chen, K.-Y. (2007) New product blockbusters: The magic and science of prediction markets. California Management Review, 50, 144-158.

Hobijn, B., Franses, P. H. and Ooms, M. (2004) Generalizations of the KPSS-test for stationarity. Statistica Neerlandica, 58, 483-502.

Holland, B. and Sam, C. (2019) A $\$ 600$ billion bill: Counting the global cost of the u.s.-china trade war. URL: https: //www . bloomberg .com/graphics/2019-us-china-trade-war-economic-fallout/.

Homaifar, G., Randolph, W. L., Helms, B. P. and Haddad, M. (1988) American presidential elections and returns of defence industry stocks. Applied Economics, 20, 985-993.

Hotten, R. (2019) Trump's threat of mexico trade war sends markets lower. URL: https://www.bbc.com/news/business48451342.

Hu, S., Cao, Y., Zhang, J., Kong, W., Yang, K., Zhang, Y. and Li, X. (2012) Granger causality's shortcomings and new causality measure. Cognitive Neurodynamics, 6, 33-42.

Huang, R. D. (1985) Common stock returns and presidential elections. Financial Analysts Journal, 41, 58-61.

Hudson, R., Keasey, K. and Dempsey, M. (1998) Share prices under tory and labour governments in the uk since 1945. Applied Financial Economics, 8, 389-400.

Hung, J.-C., Jiang, S.-J. and Chiu, C.-L. (2007) Jump risk of presidential election: evidence from taiwan stock and foreign exchange markets. Applied Economics, 39, 2231-2240.

Hyndman, R. J. and Athanasopoulos, G. (2014) Forecasting: principles and practice. OTexts.

IMF (2018) Imf. https : //www. imf .org/external/datamapper/NGDPD@WE0/WEOWORLD/USA. (Accessed on 09/27/2018).

Jacobson, G. C. (1990) Does the Economy Matter in Midterm Elections?

Jensen, M. C. (1978) Some anomalous evidence regarding market efficiency. Journal of financial economics, 6, 95-101.

Johansen, S. and Juselius, K. (1990) Maximum likelihood estimation and inference on cointegration with applications to the demand for money. Oxford Bulletin of Economics and Statistics, 52, 169-210.

Jones, S. D. (2019) Dow jones global indices methodology - s\&p dow jones indices. https ://bit .1y/2YZfZpi. (Accessed on 08/21/2019).

Karnizova, L. and Li, J. C. (2014) Economic policy uncertainty, financial markets and probability of us recessions. Economics Letters, 125, 261-265.

Kelly, B., Pástor, L. and Veronesi, P. (2016) The price of political uncertainty: Theory and evidence from the option market. The Journal of Finance, 71, 2417-2480. 
Kim, H. Y. and Mei, J. P. (2001) What makes the stock market jump? an analysis of political risk on hong kong stock returns. Journal of International Money and Finance, 20, 1003-1016.

Kim, J. H. and Shamsuddin, A. (2008) Are asian stock markets efficient? evidence from new multiple variance ratio tests. Journal of Empirical Finance, 15, 518-532.

Knight, B. G. (2004) Are Policy Platforms Capitalized into Equity Prices? Evidence from the Bush/Gore2000 Presidential Election. Journal of Public Economics, NBER Worki, 751-773.

Kwiatkowski, D., Phillips, P. C., Schmidt, P. and Shin, Y. (1992) Testing the null hypothesis of stationarity against the alternative of a unit root. Journal of Econometrics, 54, 159-178.

Lamb, R. P., Ma, K., Pace, R. D. and Kennedy, W. F. (1997) The congressional calendar and stock market performance. Financial Services Review, 6, 19-25.

Lin, C. and Wang, Y. (2004) Effects of the legislative sessions on the stock market: Evidence from taiwan. Indian Journal of Economics, 336, 1-16.

Liu, L. and Zhang, T. (2015) Economic policy uncertainty and stock market volatility. Finance Research Letters, 15, 99-105.

Lütkepohl, H. (2005) New Introduction to Multiple Time Series Analysis. Springer.

Maddala, G. and Lahiri, K. (2001) Introduction to Econometrics. West Sussex, John Wiley \&Sons Ltd.

Mahadeva, L. and Robinson, P. (2004) Unit Root Testing to Help Model Building. Handbook in Central Banking, 1-53.

Makovskỳ, P. (2014) Modern approaches to efficient market hypothesis of forex-the central european case. Procedia Economics and Finance, 14, 397-406.

Malkiel, B. (1992) Efficient market hypothesis.

Ng, B. Y. S. and Perron, P. (2001) Lag Length Selection and the Construction of Unit Root Tests with Good Size and Power. Econometrica, 69, 1519-1554.

Niederhoffer, V., Gibbs, S. and Bullock, J. (1970) Presidential elections and the stock market. Financial Analysts Journal, 111113.

Nordhaus, W. D. (1975) The political business cycle. The review of economic studies, 42, 169-190.

Oehler, A., Walker, T. J. and Wendt, S. (2013) Effects of election results on stock price performance: evidence from 1980 to 2008. Managerial Finance, 39, 714-736.

Pantzalis, C., Stangeland, D. A. and Turtle, H. J. (2000) Political elections and the resolution of uncertainty: the international evidence. Journal of banking \& finance, 24, 1575-1604.

Pástor, L. and Veronesi, P. (2013) Political uncertainty and risk premia. Journal of Financial Economics, 110, 520-545.

Persson, T., Roland, G. and Tabellini, G. (2003) How do electoral rules shape party structures, government coalitions, and economic policies? Tech. rep., National Bureau of Economic Research.

Phillips, P. and Perron, P. (1988) Testing for a Unit Root in Time Series Regressions. Biometrika, 75, 335-346.

Rambaldi, A. N. and Doran, H. E. (1996) Testing for granger non-casuality in cointegrated systems made easy. Department of Econometrics, University of New England.

Roberts, B. E. (1990a) Political institutions, policy expectations, and the 1980 election: a financial market perspective. American Journal of Political Science, 289-310. 
- (1990b) Political Institutions, Policy Expectations, and the 1980 Election: A Financial Market Perspective. American Journal of Political Science, 34, 289-310.

Rogoff, K. (1990) Equilibrium political budget cycles. American Economic Review, 80, 21-36.

Rothschild, D. (2009) Forecasting elections: Comparing prediction markets, polls, and their biases. Public Opinion Quarterly, 73, 895-916.

Roubini, N. and Sachs, J. (1989) Government spending and budget deficits in the industrial countries. Economic policy, 4, 99-132.

Santa-Clara, P. and Valkanov, R. (2003) The presidential puzzle: Political cycles and the stock market. The Journal of Finance, 58, 1841-1872.

Schwarz, G. (1978) Estimating the Dimension of a Model. Annals of Statistics, 6, 461-464.

Schwert, G. W. (2002) Tests for unit roots: A monte carlo investigation. Journal of Business \& Economic Statistics, 20, 5-17.

Scott Hacker, R. and Hatemi-J, A. (2008) Optimal lag-length choice in stable and unstable VAR models under situations of homoscedasticity and ARCH. Journal of Applied Statistics, 35, 601-615.

Seth, A. (2007) Granger causality. Scholarpedia, 2, 1667.

Sims, C. A. (1972) Money, income, and causality. The American economic review, 62, 540-552.

Smith, A. K. (2016) How presidential elections affect the stock market. URL: https : //www . kiplinger. com/article/investing/ T043-C008-S003-how-presidential-elections-affect-the-stock-market.html.

Snowberg, E., Wolfers, J. and Zitzewitz, E. (2007) Party Influence in Congress and the Economy. Quarterly Journal of Political Science, 2, 277-286.

Steeley, J. M. (2003) Making political capital: the behaviour of the uk capital markets during election'97. Applied financial economics, 13, 85-95.

Stovall, R. H. (1992) Forecasting stock market performance via the presidential cycle. Financial Analysts Journal, 5-8.

Sturm, R. R. (2009) The 'other'january effect and the presidential election cycle. Applied Financial Economics, 19, 1355-1363.

Toda, H. Y. and Yamamoto, T. (1995) Statistical inference in vector autoregressions with possibly integrated processes. Journal of econometrics, 66, 225-250.

Tokic, D. (2003) Emerging markets before the 1997 asia pacific financial crisis. Asia Pacific Business Review, 9, $105-115$.

Tuck, C. E. and Hon, L. Y. (2008) A note on the general elections and long memory: evidence from the london stock exchange. Applied Financial Economics Letters, 4, 331-335.

Urrutia, J. L. (1995) Tests of random walk and market efficiency for latin american emerging equity markets. Journal of financial research, 18, 299-309.

Volkerink, B. and De Haan, J. (2001) Fragmented government effects on fiscal policy: New evidence. Public choice, 109, 221-242.

Wang, Y., Chen, C. R. and Huang, Y. S. (2014) Economic policy uncertainty and corporate investment: Evidence from china. Pacific-Basin Finance Journal, 26, 227-243.

Wang, Y.-H. and Lin, C.-T. (2008) Empirical analysis of political uncertainty on taiex stock market. Applied Economics Letters, 15, 545-550. 
Wisniewski, T. P. (2016) Is there a link between politics and stock returns? A literature survey. International Review of Financial Analysis, 47, 15-23. URL: http://dx.doi.org/10.1016/j.irfa.2016.06.015.

Zapata, H. O. and Rambaldi, A. N. (1997) Monte Carlo Evidence on Cointegration and Causation. Oxford Bulletin of Economics and Statistics, 59, 285-298.

Zivot, E. and Wang, J. (2006) Vector autoregressive models for multivariate time series. Modeling Financial Time Series with S-Plus ${ }^{\circledR}, 385-429$. 